\title{
Affective partisan polarization and moral dilemmas during the COVID-19 pandemic*
}

\author{
Stoetzer, L. F. ${ }^{1}$, Munzert, S. ${ }^{2}$, Lowe, W. ${ }^{2}$, Çalı, B. ${ }^{2}$, Gohdes, A. ${ }^{2}$, \\ Helbling, M. ${ }^{3}$, Maxwell, R. ${ }^{4}$, and Traunmueller, R. ${ }^{3}$ \\ ${ }^{1}$ Humboldt University of Berlin \\ ${ }^{2}$ Hertie School \\ ${ }^{3}$ University of Mannheim \\ ${ }^{4}$ University of North Carolina at Chapel Hill
}

[Word Count: 3969]

Recent scholarship on affective polarization documents partisan animosity in people's everyday lives. But does partisan dislike go so far as to deny fundamental rights? We study this question through a moral dilemma that gained notoriety during the COVID-19 pandemic: triage decisions on the allocation of intensive medical care. Using a conjoint experiment in five countries we analyze the influence of patients' partisanship next to commonly discussed factors determining access to intensive medical care. We find that while participants' choices are consistent with a utilitarian heuristic, revealed partisanship influences decisions across most countries. Supporters of left or right political camps are more likely to withhold support from partisan opponents. Our findings offer comparative evidence on affective polarization in non-political contexts.

\footnotetext{
*Corresponding author Lukas F. Stoetzer, E-Mail: lukas.stoetzer@hu-berlin.de This research was generously funded by a grant from the Hertie School Faculty Activity Fund and supported by the Cluster of Excellence "Contestations of the Liberal Script" (EXC 2055, Project-ID: 390715649), funded by the Deutsche Forschungsgemeinschaft (DFG, German Research Foundation) under Germany's Excellence Strategy. We thank participants of the ECPR Joint Sessions 2021 and the WZB colloquium "Sociological Perspectives on the Corona Crisis" for valuable feedback on the paper. We thank Johannes Latmann for excellent research assistance. Finally, we are grateful to Respondi for supporting the data collection.
} 
Affective partisan polarization is on the rise. Scholars first documented affective partisan polarization in the US [Iyengar et al., 2012, Doherty et al., 2019], but similar trends exist in countries across the world Whagner, 2021, Westwood et al., 2018, Reiljan, 2020, Boxell et al., 2020, Helbling and Jungkunz, 2020]. These trends are worrisome in light of recent scholarship indicating that affective partisanship has divisive implications for many political and nonpolitical situations. The core idea is that partisan group identities trigger in-group and out-group thinking [Tajfel et al., 1979] that can extend beyond politics. For example, in-group/out-group divides are influential in dating behavior [Iyengar et al., 2012, Huber and Malhotra, 2017], economic activities [Michelitch, 2015, McConnell et al., 2018, Gift and Gift, 2015, as well as personal and professional health decisions Lerman et al., 2017, Hersh and Goldenberg, 2016.

The broad ramifications of affective partisanship raise questions about how far its effects may extend. Taken to the extreme, affective partisanship degrades and denies fundamental rights to the out-party, which can potentially have lethal consequences Kalmoe and Mason, 2019. However, measuring such extreme dynamics is difficult, because there are not many situations in which people's chance of surviving is directly and publicly debated.

In this research note, we measure affective partisanship in an extreme scenario, by studying a fundamental rights dilemma that gained notoriety during the COVID-19 pandemic: the triage for access to intensive medical care. We conducted conjoint experiments in five countries (Brazil, Germany, Italy, Poland, and the United States) in August 2020. We presented respondents with the attributes of two hypothetical patients and asked which patient they would prioritize for intensive care $1^{1}$

We find that the partisanship of the patient plays a measurable role in respondents' triage decisions. While respondents mainly rely on characteristics that are in the guide-

\footnotetext{
${ }^{1}$ Other recent papers have used a similar approach to analyze the moral dilemmas raised by COVID-19, although without examining the importance of partisanship Larsen and Schaeffer, 2021, Jin et al., 2021, Helbling et al., 2021, Reeskens et al., 2021.
} 
lines of medical associations, out-party animus also influences their priorities. Partisans on both the left and right are likely to withhold medical support from patients on the other political side. Moreover, right-party patients are more heavily penalized. We also find some evidence of in-group favoritism. Right respondents prioritize right partisan over independent patients.

This research note expands our understanding of the extreme ramifications of partisan polarization. Medical associations have clear guidelines for triage decisions and most agree on "the role of justice and benefit maximization as core principles" Jöbges et al. 2020, p.948] $\mathrm{L}^{2}$ Indeed, recent studies show that public opinion seems to side with the utilitarian core of the guidelines [Kneer and Hannikainen, 2020]. Given the prominence of these utilitarian concerns, medical triage is a least likely case for discrimination along partisan lines. Our findings of partisan discrimination are therefore all the more striking. Previous research finds that partisans are willing to dehumanize members of the out-party Martherus et al. 2019 and to rationalize physical harm against opponents Kalmoe and Mason, 2019], all of which has worrisome implications. Our study adds to this line of research by measuring out-group animus in a extreme non-political setting, and expanding our understanding of partisan affective polarization. Moreover, this is one of the first empirical studies to analyze non-political consequences of affective partisanship in a comparative perspective, suggesting these are broad dynamics that exist across the globe.

\section{Affective Partisan Polarization During the COVID-19 Pandemic}

The COVID-19 pandemic provides a unique opportunity to study cross-national differences in consequences of affective partisanship. The pandemic is a global problem

\footnotetext{
${ }^{2}$ We discuss the guidelines for the countries under study in SM section 1.3.
} 
that appeared on the social and political agenda around the world. In addition, several studies have found clear partisan divides in beliefs about the risks and development of the pandemic Allcott et al., 2020, Bhanot and Hopkins, 2020], which suggests partisan divides might play a role in how people evaluate pandemic-related issues. Yet, partisan responses to the pandemic are not uniform across countries. In the US, the Republican party has largely opposed strict lockdown measures, and studies suggest Republicans have been less likely to comply with social distancing measures Clinton et al., 2021, Gadarian et al. 2021]. In contrast, Poland's right-wing PiS has supported strict lockdown measures (see supplementary material (SM) 2.3.2). The COVID-19 pandemic is an opportunity to examine how affective partisanship may have different implications in different national contexts.

The COVID-19 pandemic also raised acute moral dilemmas about who deserves access to life-saving medical care. Providing life-saving support to all patients is a moral imperative, but it is impossible because of limited medical resources. Throughout the COVID-19 pandemic, all countries debated how to handle potential medical resource shortages, which made the issue of how to triage both prominent and salient. This allows us to study extreme partisan polarization in a realistic real-world scenario.

Clearly, most people will never need to make medical triage decisions because they are not qualified medical professionals. However, we pose our survey questions as measures of moral judgments. In that sense, the real-world scenario of medical care during COVID19 is a more realistic and accessible scenario than, for example, the question of whether to divert a trolley from killing people, which is extensively used by psychologists to study moral judgments Greene et al. 2001.

\section{A conjoint experiment on triage decisions}

Case Selection and Samples. We conducted a conjoint experiment in five countries (Brazil, Germany, Italy, Poland, and the US) in August 2020. The country selection 
is motivated by four interrelated factors: infection trajectory, party system, incumbent party, and policy responses towards the pandemic. At the time of our data collection, the five countries had very different trajectories and experiences with COVID-19. The numbers of infected and deaths were relatively high in Italy, the US and Brazil, while Germany and Poland were much less affected. Second, we compare the two-party system of the US to the multi-party systems in the other countries. Third, during our study period the governing party in the US, Brazil and Poland had a right-wing leadership, whereas Germany and Italy were governed by centrist coalitions. Fourth, we observe the policy stance toward COVID-19, where our sample displays variation with respect to position of right parties (See SM 2.3.2). The survey sample includes 6,415 individuals from the five countries, recruited from a commercial access panel using quotas to reflect the age, gender, and education distribution of the adult population 3

Conjoint Experiment and Attribute Dimensions. The task is framed by the notion that an increasing number of COVID-19 cases could overwhelm the healthcare system and medical staff would have to decide which patients should receive intensive medical care. It then presents respondents with two patient profiles and asks them which of the two they would prioritize 4 The patients' profiles include age (at four different levels: 21, 42, 61, and 76), gender (female and male), whether the patient has children or not, occupation (unemployed, cook, professor, physician, and nurse), arrival at the hospital (first, second, at the same time), the survival chance of the patient (20\%, 50\%, and 80\%), and the partisanship of the patient (left partisan, right partisan, none). Respondents are presented four patient pairs. The attribute levels are randomized, except for the arrival at the hospital 5 The order of the attributes is randomized over respondents but kept

\footnotetext{
${ }^{3}$ The sample size varies between countries. In Germany it is twice as large as in the other countries. See SM 3.1 for more detail.

${ }^{4}$ Decision-making between two patients approximates decisions with multiple alternatives in medical studies Redelmeier and Shafir, 1995.

${ }^{5}$ Only the first patients level was randomized, the second patients' arrival to the hospital logically follows from the first.
} 
constant for the four decisions.

The survival chance of the patient most directly aligns with utilitarian ethical guidelines, according to which patients with higher survival chances should be prioritized ${ }^{6}$ Other aspects are in some of the guidelines: the age of the respondent (younger patients should be prioritized), the job of the patient (patients with "system-relevant" jobs are prioritized), children, and the arrival at the hospital ("first-come-first-serve" principal). Based on these, we derive hypotheses of how the patient profiles influence respondents' priorities. The full list of hypotheses is described in the pre-analysis plan (see SM 6).

The attribute that we use to test the implication of the affective partisan polarization theory is the partisanship of the patient. We choose different partisan attributes in the five countries. In the bi-partisan system of the US, we use Republican, Democrat, and none. In other contexts, in addition to a non-partisan level we selected parties that stand on the left and the right of the political spectrum. For Germany, we choose the Alternative for Germany (AfD) and the Alliance90/The Greens. For Poland, the Law and Justice Party (PiS) and the Civic Platform (PO). For Brazil, the Social Liberal Party (PSL, Bolsonaro) and the Workers' Party (PT, Lula), referring to the presidential candidates. For Italy, the Lega and Italia Viva. The supplementary material provides more details on the selection and information about the ideological and lock-down positions of the parties (SM 2.3).

The effects of the partisan attributes of the patients should be pronounced among respondents who are affectively polarized. In line with previous research [see e.g. Druckman et al., 2020, Wagner, 2021, Harteveld, 2021, we measure affective polarization using rating-scores for the different parties. The survey contains a battery of 11-pt. rating scores for the different parties. The difference between the rating scores for the left party and the right party serves as our measure.7 We also describe the results when using a

\footnotetext{
${ }^{6}$ The survey explicitly notes that the stated survival rates already take into account influences of factors such as age and gender. A manipulation check reveals that not all respondents understood this fact (See SM 3.2).

${ }^{7}$ For descriptive statistics please see the SM 4.2
} 


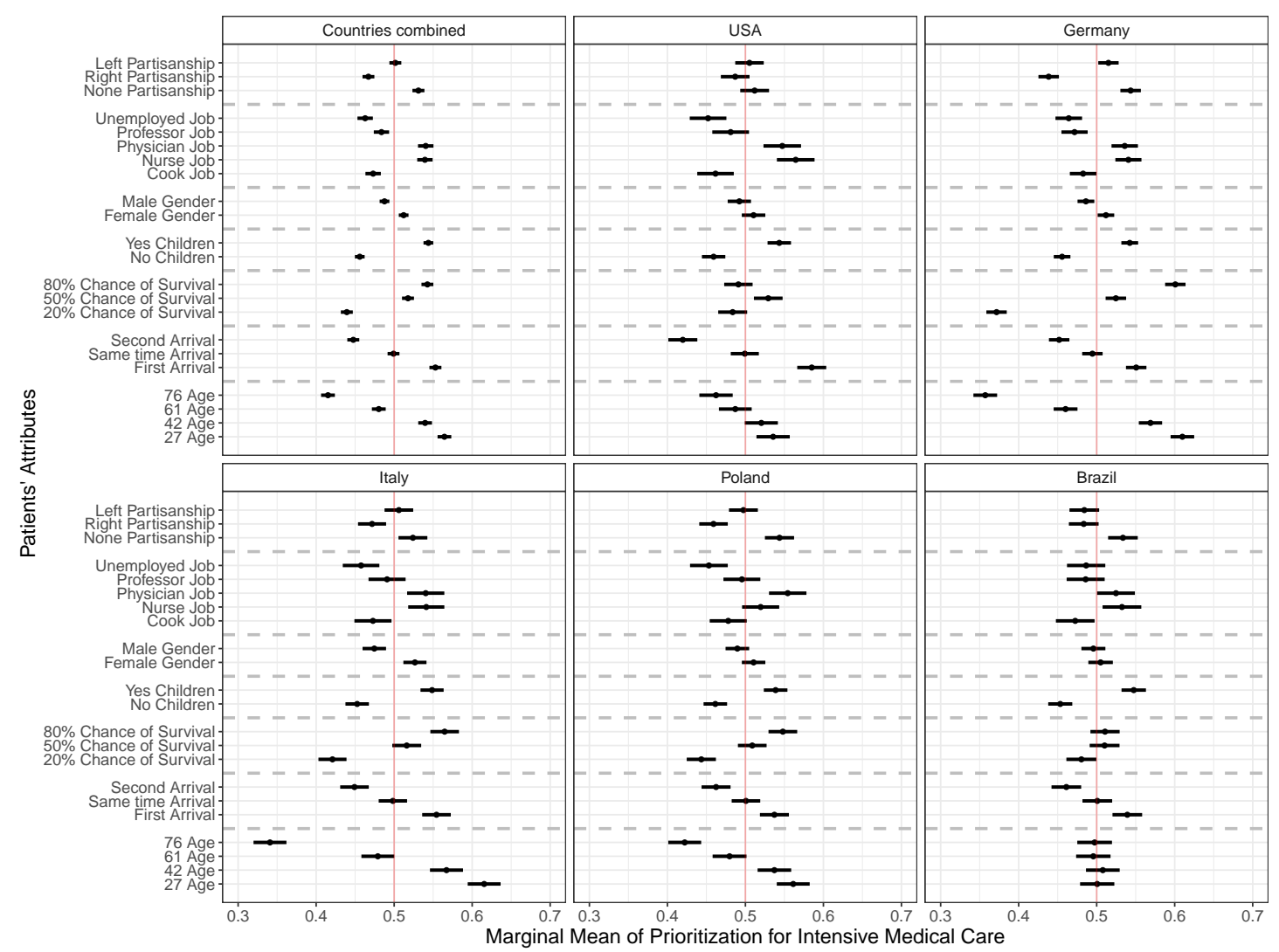

Figure 1: Marginal means of prioritizing patient for intensive Medical Care in the five country and combined samples.

partisan identification question instead of the rating score-difference in SM 5.4.

To evaluate the effect of patient attributes on respondents' priorities, we present the marginal means (MM) and the average marginal component (interaction) effects (AMCIE) of the prioritization for intensive care. We present results country-wise and pooled, combining all respondents (weighting for sample size). We estimate the MM and AMCIE using linear regression models and clustered standard errors.

\section{Results}

Figure 1 shows the marginal means for the different attributes in the five countries, and the sample size-weighted pooled effects. The results reveal that respondents' decisions 
broadly align with the medical guidelines. First, the core criteria of the guidelines - the chance of survival - plays a central role in the decisions. With $54 \%$ selection probability a patient with an $80 \%$ survival chance has a 10pp (percentge points) higher chance of being prioritized compared to the $44 \%$ selection probability of a patient with $20 \%$ chance of survival. This difference is particularly pronounced in Germany (23pp), Italy (14pp), and Poland (10pp). Second, the age of the patient is crucial. Respondents generally prioritize young patients: they prioritize patients with an age of 76 only $41 \%$ of the times, but young patients with an age of $2656 \%$ of times. In Italy, this difference is particularly large with $27 \mathrm{pp}$. Third, respondents prioritize patients with system-relevant jobs but the effects are relatively small 8 Nurses and Physicians roughly have a $6 \%$ higher chance compared to cooks. Fourth, respondents prioritize patients with children (45\% versus $54 \%$ ) and slightly favor female patients (51\%). Finally, arriving second at the hospital decreases the selection chances from $55 \%$ to $45 \%$, with particularly strong differences in the US (17pp).

The results show that when averaging across all five countries, the partisanship of the patient has a small influence on the priorities of the respondents. Across all countries, respondents prioritize a patient with no partisanship with 53\%, left partisans with 50\%, and right partisans with $46 \%$. The difference vary between the country samples. While there is no difference in the US sample, this pattern is more pronounced in Germany, Italy, and Poland. In Germany, a AfD patient is prioritized only $43 \%$ of the times. It has to be pointed out that given the varying context, size, tradition and supporter group of the right and left parties in our sample, these average differences are difficult to compare across context. However, the results show that compared to the other differences described above, patients' partisanship are less relevant on average. When asking respondents in an open question format what attributes should matter, only 1\%-2.5\% name partisanship. A majority names survival chances as a important feature (See SM

\footnotetext{
${ }^{8}$ For perceived job relevance in the different countries see SM 4.1
} 


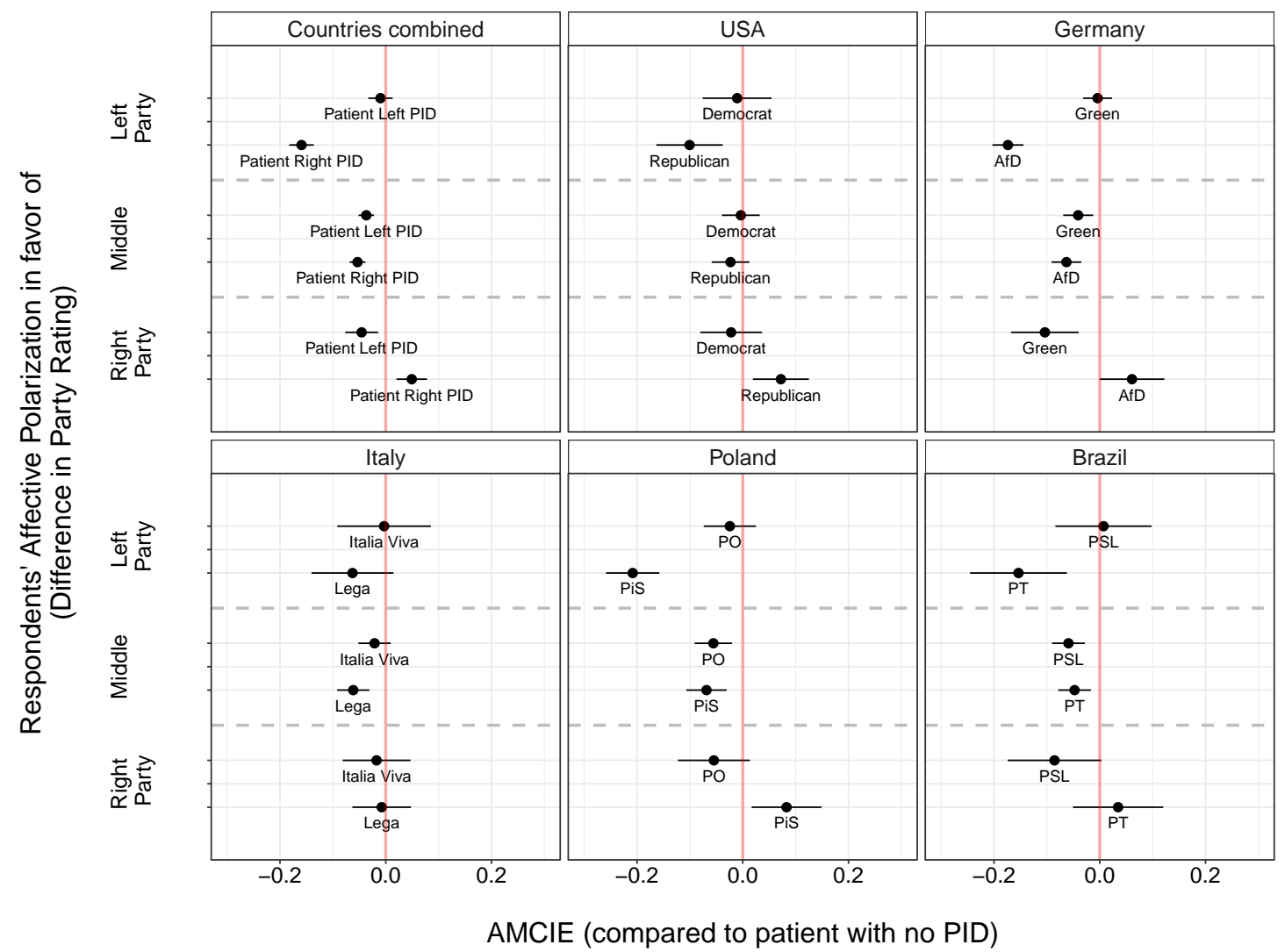

Figure 2: Average Marginal Component Effects of triage patient's partisan affiliation conditional on respondent's affective polarization

5.6). Furthermore, an analysis of attribute importance using random forests in the supplementary materials reveals that age, children, and the survival chance seem to matter most (see SM 5.7).

To evaluate the partisan affective polarization in triage decisions, we present the average marginal component interaction effects conditional on the difference in rating scores. Figure 2 shows the effects among respondents with low, middle, and high rating score difference between the respective right and left party ${ }^{9}$ The panel in the top left reveals out-party animus. Affectively polarized left respondents, who give a low evaluation of

\footnotetext{
${ }^{9}$ We define the groups based on fix cut-offs of -5 and +5 across all countries. We discuss results when using quantiles of rating-scores differences instead in SM 5.3 and in SM 5.6 provide the linear interaction effect estimates. We further refer to conditional effects on respondents' partisanship in SM 5.5. The general conclusion is unchanged.
} 
the right parties and a high evaluation of the left, downgrade patients with a right partisanship by $16 \mathrm{pp}$ compared to patients with no partisanship. The same left respondents do not prioritize patients with a left partisanship. For affectively polarized right respondents we find they are 5pp less likely to prioritize left partisan patients but 5pp more likely to prioritize patients with right partisanship compared to independent patients. Respondents in the middle slightly prioritize patients with no partisan attachments (52\%) to both left (49\%) and right partisan (48\%) patients, resulting in ACMIE of $-3 \mathrm{pp}$ for the left and -5pp for the right. The pattern could be due to the fact that independents dislike partisans and therefore downgrade both groups [Klar et al., 2018.

The country results mimic these general patterns. In the US, Respondents with high ratings of the Democratic party and low ratings of the Republican party downgrade Republican patients with 10pp. We find in-group favoritism among Republicans, with polarized Republican supporters prioritizing Republican patients (7pp) compared to nonpatients. There is no clear difference between polarized Republican supporters when comparing Democratic patients to patients with no party affiliation. In other country contexts, out-party animus towards the right partisan patients is even more pronounced. In Poland, Brazil and Germany, left-polarized respondents demote patients with right partisanship with more 15,17, and 20pp. Right-polarized respondents also downgrade left patients in these countries (with 5pp in Brazil, 9pp in Poland, and 10pp in Germany), with the extend of the out-party animus effect being slightly smaller. In Germany and Poland, right-polarized respondents show signs of in-group favoritism, prioritizing rightpartisan patients with 6 and 8pp compared to independent patients. In Italy, polarized respondents do not differentiate as strongly based on Italia Viva or Lega partisanship. In some context, it shows that respondents in the middle downgrade right and left-party patients (Brazil, Germany, Poland).

These patterns reveal evidence of out-party animus among affectively polarized left and right respondents and in-group favoritism among affectively polarized right respondents. 
Out-party animus may be particularly pronounced among left respondents because they believe right-wing partisans are less compliant with COVID regulations. This would influence the perceived deservingness for prioritized treatment, a potentially strong driver of the decisions in moral dilemmas van Oorschot, 2000, 2006. Left-right differences in out-party animus, hence, might be a compound effect of beliefs about the compliance behavior of the patient and the partisanship itself. We cannot tease apart these two possibilities with our research design. Yet, suggestive evidence from the lock-down positions of the parties suggests it is not merely about right-wing approaches to COVID. The AfD in Germany has actively opposed stronger lock-down measures, but the PiS in Poland supported lock-down measures and called for compliance (See SM 2.3.2). Both right partisan patients' cues trigger equally strong reactions among left respondents, suggesting that the effect is not only due to the position advocated by the patients' party, but a general reaction towards the right party partisanship 10 Another possibility is that partisan cheerleading effects induce differential levels of partisan responses in surveys Bullock and Lenz, 2019, but we leave this for future research to examine.

\section{Discussion}

How far-reaching are the consequences of affective partisan polarization in times of the global COVID-19 pandemic? Our results suggest affective partisan polarization has nonpolitical consequences in countries across the globe. When asking which patient should receive potentially life-saving treatment for COVID-19, respondents penalize outparty patients. This reveals that out-party animus matters for difficult moral decisions when healthcare resources are distributed. The pattern is particularly strong in Poland and Germany, showing the behavioral nonpolitical relevance of affective polarization beyond the US context.

\footnotetext{
${ }^{10}$ In addition, partisans do not generally admit to riskier behavior and compliance in all countries (See SM 4.3 and SM 4.4), questioning the clear attribution of non-compliant behavior for right partisans in all contexts under study.
} 
The findings address pressing issues during the global pandemic. Can the COVID-19 pandemic provide citizens with a sense of shared fate that bridges political divides in favor of a common identity? Or does the zero-sum nature of scarce health resources further increase political conflicts and inflame tribal partisan behavior? The answer to these questions is a vital ingredient for successfully combating the current global health crisis Van Bavel et al. 2020.

There is no reason to expect that partisanship matters in real-world hospital care. Medical staff typically do not know the partisan affiliation of their patients, and medical association guidelines strongly prohibit such discrimination. We are confident that these morally and emotionally difficult decisions are in the hands of trained medical personnel. Nonetheless, the hypothetical triage decision helps us understand how ordinary people think about people with different party affiliations. Our triage experiment provides a more realistic insight into the effect of affective polarization on moral judgments than other more abstract moral dilemmas like the trolley problem. The triage of patients with COVID-19 symptoms is an existing problem that is widely discussed in public and we show that affective partisan polarization can impair moral judgment in these extreme situations.

\section{References}

Hunt Allcott, Levi Boxell, Jacob Conway, Matthew Gentzkow, Michael Thaler, and David Yang. Polarization and public health: Partisan differences in social distancing during the coronavirus pandemic. Journal of Public Economics, 191:104254, 2020.

Syon P Bhanot and Daniel J Hopkins. Partisan polarization and resistance to elite messages: Results from survey experiments on social distancing. Journal of Behavioral Public Administration, 3(2), 2020.

Levi Boxell, Matthew Gentzkow, and Jesse M Shapiro. Cross-country trends in affective polarization. Technical report, National Bureau of Economic Research, 2020.

John G Bullock and Gabriel Lenz. Partisan bias in surveys. Annual Review of Political Science, 22:325-342, 2019. 
J Clinton, J Cohen, John Lapinski, and Marc Trussler. Partisan pandemic: How partisanship and public health concerns affect individuals' social mobility during covid-19. Science advances, 7(2):eabd7204, 2021.

Carrol Doherty, Jocelyn Kiley, and Nida Asheer. Partisan antipathy: More intense, more personal. Pew Research Center, 2019.

James N Druckman, Samara Klar, Yanna Krupnikov, Matthew Levendusky, and John Barry Ryan. How affective polarization shapes americans' political beliefs: A study of response to the covid-19 pandemic. Journal of Experimental Political Science, pages $1-12,2020$.

Shana Gadarian, Sara Wallace Goodman, and Thomas Pepinsky. Partisanship, health behaviors, and policy attitudes in the early stages of the covid 19 pandemic. PLOSOne, 2021.

Karen Gift and Thomas Gift. Does politics influence hiring? evidence from a randomized experiment. Political Behavior, 37(3):653-675, 2015.

Joshua D Greene, R Brian Sommerville, Leigh E Nystrom, John M Darley, and Jonathan D Cohen. An fmri investigation of emotional engagement in moral judgment. Science, 293(5537):2105-2108, 2001.

Eelco Harteveld. Ticking all the boxes? a comparative study of social sorting and affective polarization. Electoral Studies, 72:102337, 2021.

Marc Helbling and Sebastian Jungkunz. Social divides in the age of globalization. West European Politics, 43(6):1187-1210, 2020.

Marc Helbling, Rahsaan Maxwell, Simon Munzert, and Richard Traunmüller. Does every life count the same? evidence from a triage experiment. 2021.

Eitan D Hersh and Matthew N Goldenberg. Democratic and republican physicians provide different care on politicized health issues. Proceedings of the National Academy of Sciences, 113(42):11811-11816, 2016.

Gregory A Huber and Neil Malhotra. Political homophily in social relationships: Evidence from online dating behavior. The Journal of Politics, 79(1):269-283, 2017.

Shanto Iyengar, Gaurav Sood, and Yphtach Lelkes. Affect, not ideology: a social identity perspective on polarization. Public opinion quarterly, 76(3):405-431, 2012.

Liyin Jin, Yunhui Huang, Yongheng Liang, and Qiang Zhang. Who gets the ventilator? moral decision making regarding medical resource allocation in a pandemic. Journal of the Association for Consumer Research, 6(1):000-000, 2021.

Susanne Jöbges, Rasita Vinay, Valerie A Luyckx, and Nikola Biller-Andorno. Recommendations on covid-19 triage: international comparison and ethical analysis. Bioethics, 2020. 
Nathan P. Kalmoe and Lilliana Mason. Lethal mass partisanship: Prevalence, correlates, \& electoral contingencies. In National Capital Area Political Science Association American Politics Meeting, 2019.

Samara Klar, Yanna Krupnikov, and John Barry Ryan. Affective polarization or partisan disdain? untangling a dislike for the opposing party from a dislike of partisanship. Public Opinion Quarterly, 82(2):379-390, 2018.

Markus Kneer and Ivar Rodríguez Hannikainen. Triage dilemmas: A window into (ecologically valid) moral cognition. 2020.

Mikkel Haderup Larsen and Merlin Schaeffer. "healthcare chauvinism during the covid19 pandemic". Journal of Ethnic and Migration Studies, 47(7):1455-1473, 2021.

Amy E Lerman, Meredith L Sadin, and Samuel Trachtman. Policy uptake as political behavior: evidence from the affordable care act. American Political Science Review, 111(4):755-770, 2017.

James L Martherus, Andres G Martinez, Paul K Piff, and Alexander G Theodoridis. Party animals? extreme partisan polarization and dehumanization. Political Behavior, pages 1-24, 2019.

Christopher McConnell, Yotam Margalit, Neil Malhotra, and Matthew Levendusky. The economic consequences of partisanship in a polarized era. American Journal of Political Science, 62(1):5-18, 2018.

Kristin Michelitch. Does electoral competition exacerbate interethnic or interpartisan economic discrimination? evidence from a field experiment in market price bargaining. The American Political Science Review, 109(1):43, 2015.

Donald A Redelmeier and Eldar Shafir. Medical decision making in situations that offer multiple alternatives. Jama, 273(4):302-305, 1995.

Tim Reeskens, Femke Roosma, and Evelien Wanders. The perceived deservingness of covid-19 healthcare in the netherlands: a conjoint experiment on priority access to intensive care and vaccination. BMC Public Health, 21(1):1-8, 2021.

Andres Reiljan. Fear and loathing across party lines (also) in europe: Affective polarisation in european party systems. European journal of political research, 59(2):376-396, 2020 .

Henri Tajfel, John C Turner, William G Austin, and Stephen Worchel. An integrative theory of intergroup conflict. Organizational identity: A reader, 56:65, 1979.

Jay J Van Bavel, Katherine Baicker, Paulo S Boggio, Valerio Capraro, Aleksandra Cichocka, Mina Cikara, Molly J Crockett, Alia J Crum, Karen M Douglas, James N Druckman, et al. Using social and behavioural science to support covid-19 pandemic response. Nature Human Behaviour, 4(5):460-471, 2020. 
Wim van Oorschot. Who should get what, and why? on deservingness criteria and the conditionality of solidarity among the public. Policy \& Politics, 28(1):33-48, 2000.

Wim van Oorschot. Making the difference in social europe: deservingness perceptions among citizens of european welfare states. Journal of European Social Policy, 16(1): 23-42, 2006.

Markus Wagner. Affective polarization in multiparty systems. Electoral Studies, 69: 102199, 2021.

Sean J. Westwood, Shanto Iyengar, Stefaan Walgrave, Rafael Leonisio, Luis Miller, and Oliver Strijbis. The tie that divides: Cross-national evidence of the primacy of partyism. European Journal of Political Research, 57(2):333-354, 2018. 


\section{Supplementary material: Affective partisan polarization and moral dilemmas during the COVID-19 pandemic}

Stoetzer, L. F. ${ }^{1}$, Munzert, S. ${ }^{2}$, Lowe, W. ${ }^{2}$, Çalı, B. ${ }^{2}$, Gohdes, A. ${ }^{2}$, Helbling, M. ${ }^{3}$, Maxwell, R. ${ }^{4}$, and Traunmueller, R. ${ }^{3}$

${ }^{1}$ Humboldt University of Berlin

${ }^{2}$ Hertie School

${ }^{3}$ University of Mannheim

${ }^{4}$ University of North Carolina at Chapel Hill

March 2, 2022 


\section{Contents}

1 Research Design 3

1.1 Ethical Considerations $\ldots \ldots \ldots \ldots \ldots \ldots$

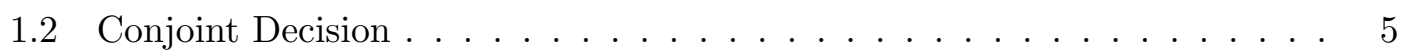

1.3 Survey Questions $\ldots \ldots \ldots \ldots \ldots \ldots$

$\begin{array}{lll}2 & \text { Countries in study } & 8\end{array}$

$2.1 \quad$ COVID Cases over time $\ldots \ldots \ldots \ldots \ldots$

$2.2 \quad$ Medical Guidelines for Triage Decisions . . . . . . . . . . . . . . . . . . . 10

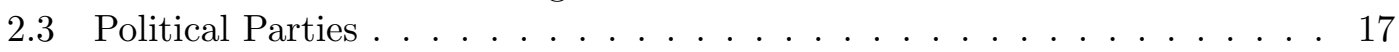

2.3 .1 General Left-Right Positions . . . . . . . . . . . . . . . . 17

2.3 .2 COVID Lockdown Positions . . . . . . . . . . . . . . . . . 17

3 Sample Information 22

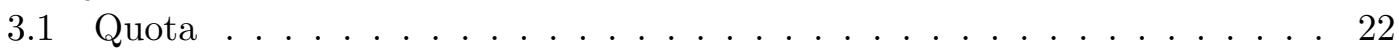

3.2 Attention Check $\ldots \ldots \ldots \ldots \ldots \ldots \ldots \ldots$

\begin{tabular}{|ll}
4 & Descriptive Statistics \\
\hline
\end{tabular}

4.1 Job Relevance Perception . . . . . . . . . . . . . . . . . . . . . 25

4.2 Affective Polarization $\ldots \ldots \ldots \ldots \ldots \ldots$

4.3 Experience with COVID $\ldots \ldots \ldots \ldots \ldots \ldots$. . . . . . . . . . . . . . 27

4.4 Compliance and risk behavior $\ldots \ldots \ldots \ldots \ldots \ldots$

5 Additional Analysis $\quad \mathbf{3 0}$

5.1 Average marginal component effects . . . . . . . . . . . . . . . . 30

5.2 Marginal Means conditional on Affective Polarization . . . . . . . . . . . . . 31

$5.3 \quad$ Average Marginal Component Interaction Effect Affective Polarization

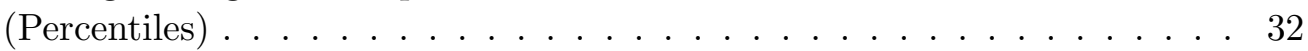

\begin{tabular}{lll}
5.4 & Average Marginal Component Interaction Effect for Sociodemographics \\
\hline 5 & 33
\end{tabular}

5.5 Average Marginal Interaction Component Effect Partisanship . . . . . . . . 34

\begin{tabular}{ll}
5.6 & Average Marginal Interaction Component Effect with Linear Interaction \\
\hline & Effect $\ldots \ldots \ldots \ldots \ldots \ldots$
\end{tabular}

5.7 Evaluating Effects among Respondents who Pass the Attention Check . . 37

5.8 Evaluating Attribute Importance from Open Survey Answers . . . . . . . 38

5.9 Evaluating Attribute Importance using Random Forests . . . . . . . . . . 41

6 Pre-Analysis Plan 43

$6.1 \quad$ Anonymized Pre-Analysis Plan . . . . . . . . . . . . . . . . . . . . 43

6.2 Deviations from Pre-Analysis Plan . . . . . . . . . . . . . . . 55 


\section{Research Design}

\subsection{Ethical Considerations}

The study was approved by the Dean's office at which serves in lieu of an ethics committee. Our research complies with GDPR requirements and all relevant ethical regulations, as documented in the German Research Foundation's Code of Conduct Guidelines for Safeguarding Good Research Practice. The research also adheres to the Principles and Guidance for Human Subjects Research approved by the APSA Council. In the following we discuss some additional considerations:

Participant recruitment and compensation: In partnership with the online survey firm respondi, panelists were invited to participate in a study on attitudes in the context of the COVID-19 pandemic. Participation was voluntary. The survey design and programming were implemented on our end. The access panel provider and its local partners compensate their participants with their standard rates of cash transfers or platform-specific currencies for voluntary participation. In our case, participants were compensated with $0.50 €$ in the US, $0.75 €$ in Poland and Germany, and 17 Korpus points in Brazil and Italy, for their participation in the 15 minute survey.

Informed Consent: At the beginning of the survey, we obtained voluntary and informed consent from participants. We explain the research project, study purpose, the risk and benefits and described direct contact details to inquire further information. Figure 1 provides a screenshot of the text as presented to the (US) participants. Participants in other countries received a translated but otherwise identical version.

Deception: The research design does not use any form of deception.

Confrontation with triage decisions: We renew voluntary consent before confronting respondents with the triage decisions to minimize the risk of re-traumatization due to respondents' personal experiences. The survey text reads: "Although these are not profiles of real patients, we are aware that this kind of decision could be unpleasant or repulsive to you. Therefore, if you do not want to make these decisions, you can skip the questions without answering them."

Confidentiality: The identities of research participants are kept confidential. Contacting details are kept with the survey firm respondi. The anonymized response data is stored with the researchers. The anonymized data will be shared with the research community. 
Consent

Before you decide to participate in this study, it is important that you understand why the research is being done and what it will involve. Please take the time to read the following information carefully. Please contact the researchers if you need more information.

Research Project

The title of the research project is "Life in Times of COVID-19". This research project is being conducted by

Purpose of the Research

This is a study on public opinion and behavior during the COVID-19 pandemic. Citizens in multiple countries are surveyed. Your participation is voluntary. Participation involves completion of a survey and the option to participate in another short follow-up survey. You may choose not to answer any or all questions.

\section{Study Procedure}

You will be asked a series of questions in an online survey - mostly you will answer by clicking boxes to supply your opinion or experience. You may choose not to answer any questions that you are not comfortable answering, and you can withdraw from the survey at any time.

\section{Risks and Benefits}

Risks to participation are minimal, and while there are no direct benefits, you will be helping to further scientific understanding of current public opinion and behavior. Researchers involved in the study will protect your personal information, and others will not be able to connect your responses to personally identifiable information. Any personal information that could identify you will be removed or changed before files are shared with other researchers or results are made public.

\section{Contact}

Questions about this project may be directed to

Any concerns can be directed

\section{to}

I hereby confirm that I am at least 18 years old, that I have read, understood, and agree with the terms detailed above. Do you wish to participate in this survey?

I hereby confirm that I am at least 18 years old, that I have read, understood, and agree with the terms detailed above. Do you wish to participate in this survey?

Figure 1: Screenshot of informed consent 


\subsection{Conjoint Decision}

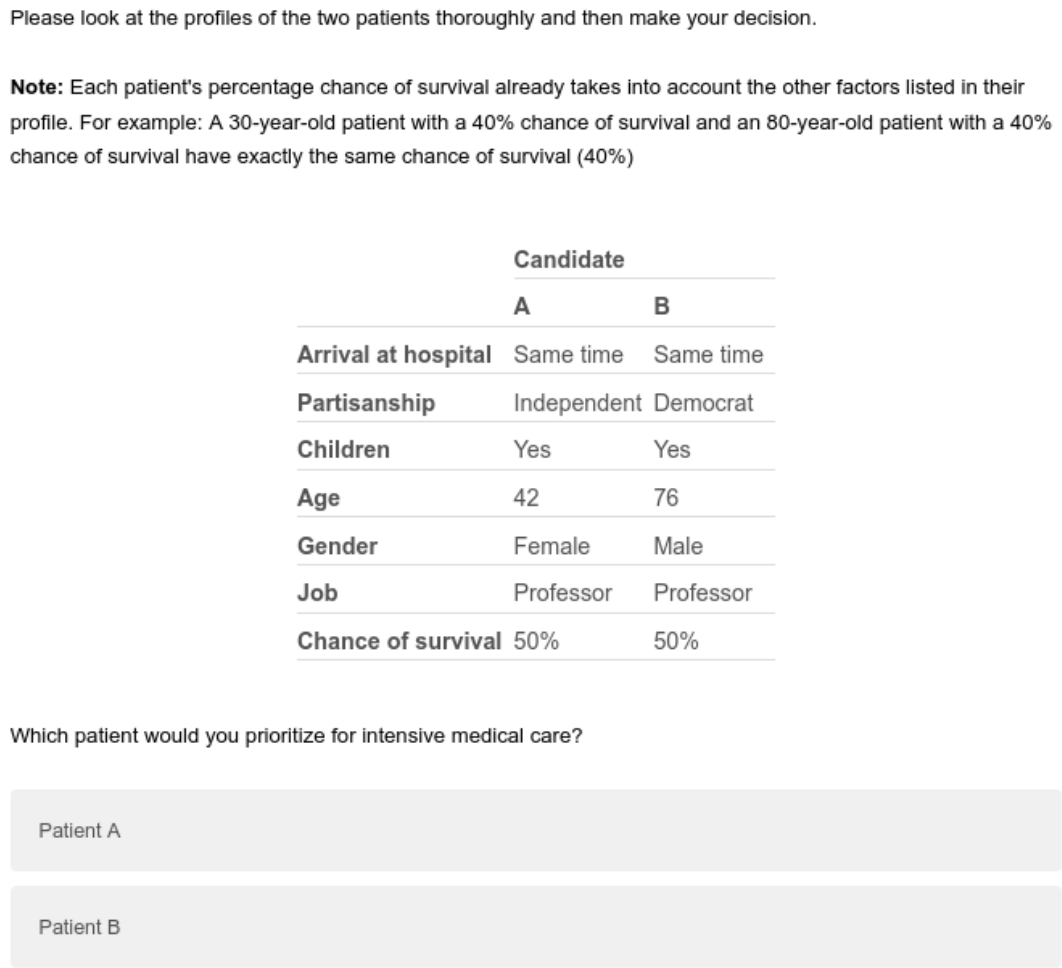

Figure 2: Example conjoint decision task

\subsection{Survey Questions}

This section gives details on the survey question of the online questionnaire that we rely upon in our analysis. The questions have been translated by a native in the respective languages.

- Gender Please state your gender. Male, Female, Other

- Education ADD

- Year of birth Would you please tell us your year of birth? 1920-2005

- Children Do you have children? No, Yes 1 child, Yes 2 children, Yes 3 children, Yes 4 or more children 
- Job employment status What is your current employment status? Unemployed, [other categories]

- Job What is/was the name or title of your main job? Open item

- Partisan affiliation What do you think about the political parties in general? "I have a very negative view of this party" $(-5)$ to "I have a very positive view of this party" $(+5)$

- Partisanship (US) Generally speaking, do you usually think of yourself as a Republican, a Democrat, an independent, or what?

- Republican

- Democrat

- Independent

- Something else (please specify):

[If Democrat/Republican] Would you call yourself a strong Democrat/Republican or a not very strong Democrat/Republican?

- Strong Democrat/Republican

- Not very strong Democrat/Republican

[If Independent] Do you think of yourself as closer to the Republican Party or to the Democratic Party?

- Closer to the Republican Party

- Closer to the Democratic Party

- Neither

- Partisanship (Other Countries) In [country], many people tend to support a certain political party for a long time, although they also vote for another party from time to time. How is that with you: Are you generally inclined towards a particular party? And if so, which one?

[If Party] How strongly or how weakly do you lean - all things considered - toward the party $[\ldots]$ ? Strong, somewhat strong, moderate, somewhat weak, weak.

- Job relevance How essential do you consider the following professional groups to keep a country running? Categories: Doctors, Nurses,Cooks, Journalists, Professors, Police officers. Scale: Not essential at all, Not very essential, Somewhat essential, Very essential, Don't know 
- Attention Check Thinking back on the previous questions: Which of the following people do you think has a higher chance of survival after intensive medical care?" The answering options are "An 80-year-old man with a $40 \%$ chance of survival after the use of intensive care measures", "A 40-year-old man with a $40 \%$ chance of survival after using intensive care measures", and "Both have the same chance of survival"

- Experience with COVID Do you know of anyone (including yourself, family, friends, acquaintances, colleagues, or neighbors) who has been infected by COVID19? "No", "Yes, 1-3 people", "Yes, more than 3 people"

- Compliance with COVID measures With the pandemic that has taken place over the past few months, the following recommendations have been issued: Keep distance; wash hands frequently; wear masks if keeping a distance is not possible. To what extent do you comply with these recommendations? "I almost always follow them", "I try to adhere to them, but often I do not succeed (e.g., for professional reasons)" , "I barely adhere to them","I am not aware of these recommendations".

- Risk behavior In the last seven days: How often have you done the following? Categories: "Used public transport", "Visited a restaurant, café or bar", "Met with friends, relatives or acquaintances in person". Scale: Never, Once this week, Several times this week, Every day, Don't know. 


\section{Countries in study}

\subsection{COVID Cases over time}

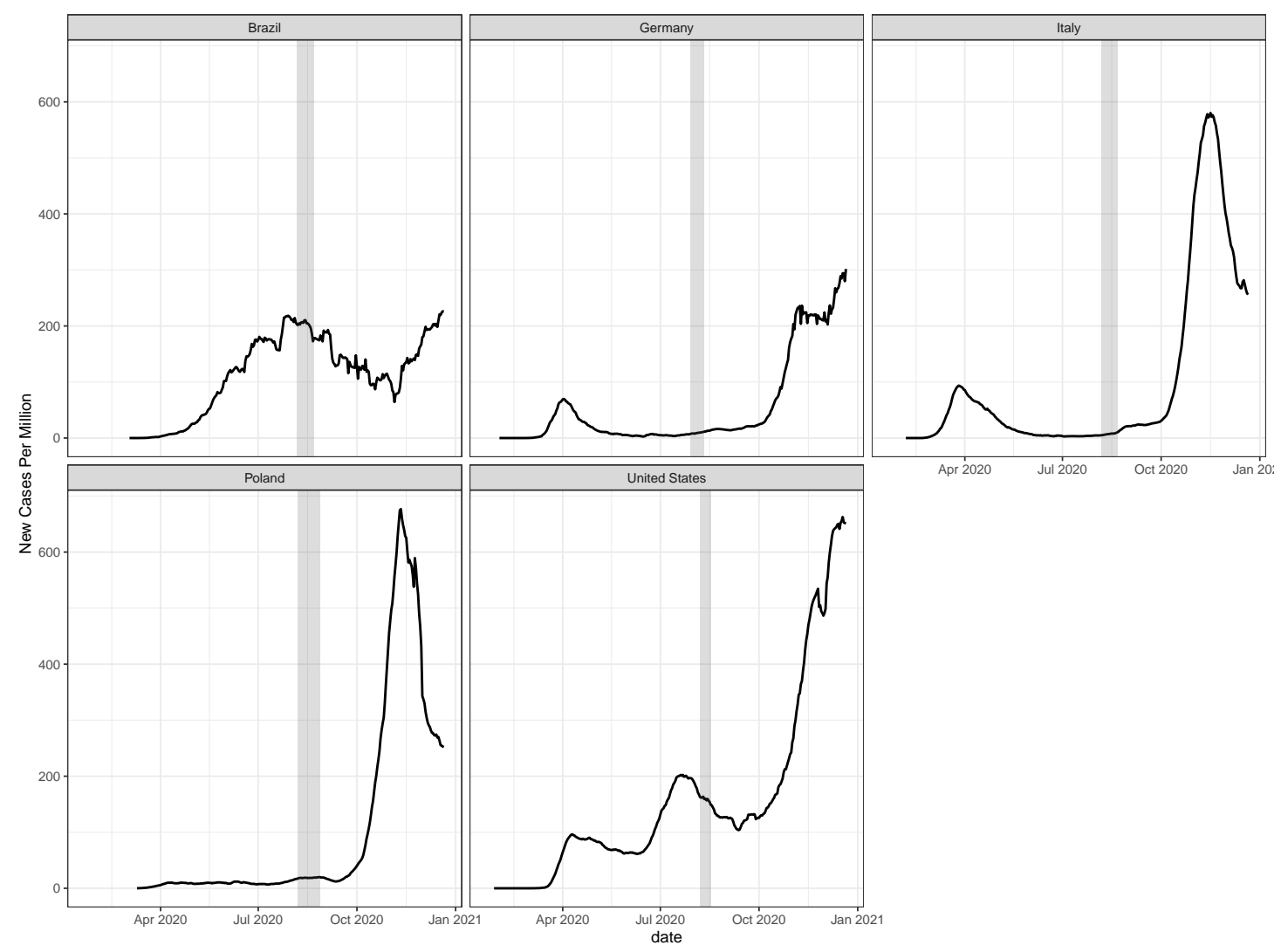

Figure 3: Corona Cases 2020 in five countries under study. Source: Grey area shows field period of survey.

This section provides background on COVID-situation in the five countries. The field period in the five countries started on 29 July and ended on 28 August. During this time the countries were at different stages in terms of the spread of the corona-virus. Figure 3 shows the reported corona-cases in the countries in 2020. During the field period, the three European countries found themselves at comparable low levels in the summer. Both Italy and Germany had experienced a first wave in April, during which particularly Italy experienced high case numbers. In Brazil the numbers were at high levels during the field period, with around 200 new cases per one million. In the United States the cases decreased slightly during the field period, but were at higher levels compared to the European countries. During the field period, both Brazil and USA 
were among the countries with most cases. All studies took place before the second wave increased case numbers in the European countries and the US.

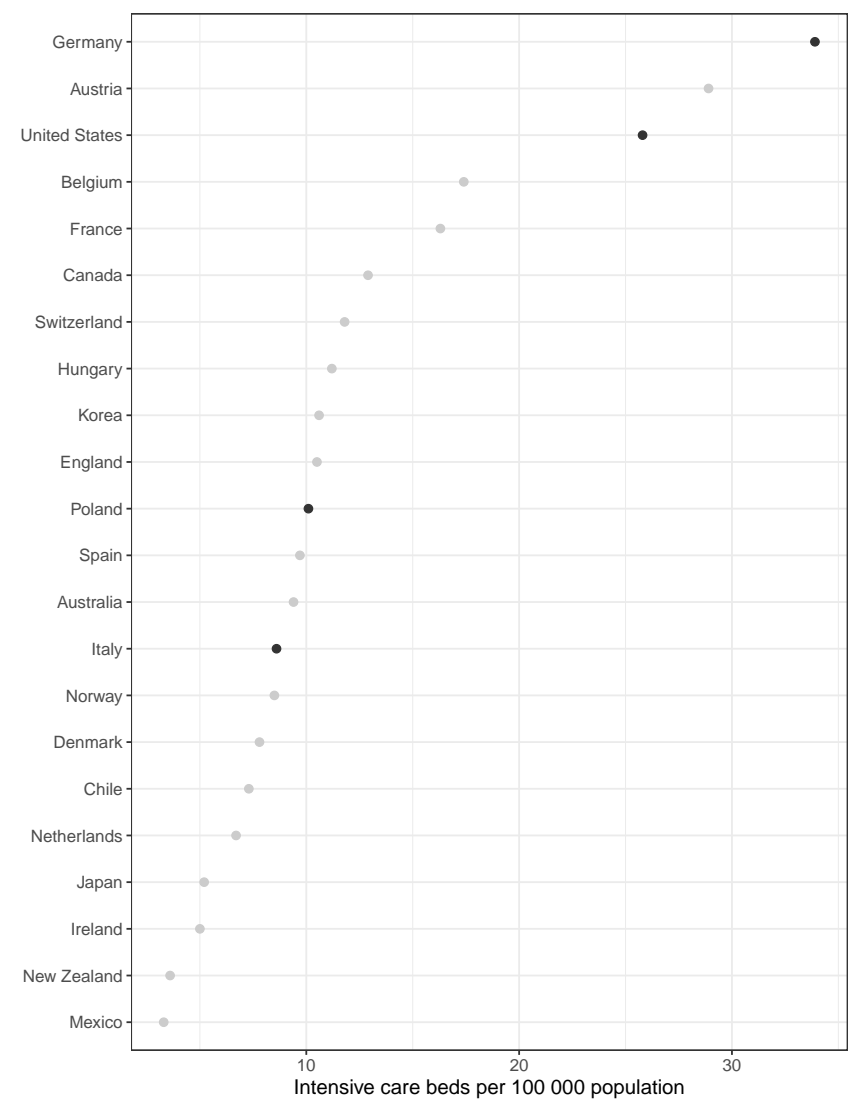

Figure 4: Intensive Bed Units in OECD Countries. Year in parenthesis. Source: . Countries in sample highlighted.

The countries differ with respect to their intensive care units. Figure 4 shows the number of intensive bed units per 100'000 population for OECD countries. Both Germany (33.9 ICU) and the United States (25.8) are found at the top end. Italy (8.6) and Poland (10.1) have lower levels and, hence, have potentially have deal with scare resources earlier. While not reported in the OECD Data, Brazil has a comparable share of IUC Beds with approximately 10 bed for every 10,0000 inhabitants Palamim and Marson, 2020. 


\subsection{Medical Guidelines for Triage Decisions}

This section gives an overview of existing medical guidelines on triage decisions in the countries under study. We, first of all, adopt and extend Jöbges et al. 2020 description of medical guidelines for Italy, the USA, Germany, Brazil, and Poland. Germany, Italy, and the USA have dedicated institutions that provide guidelines and ethical recommendations. Poland and Brazil have no publicly available and published guidelines for triage decisions. In Poland, we rely on correspondence with the Polish Health Ministry confirming that triage decisions are guided by general rules of medical ethics. In Brazil, the health ministry responded to a freedom of information query that there are no central guidelines and decisions are made based on clinical assessments by hospitals.

\begin{tabular}{|c|c|c|c|c|c|}
\hline & Italy & USA & Germany & Poland & Brazil \\
\hline $\begin{array}{l}\text { Issuing } \\
\text { body }\end{array}$ & $\begin{array}{l}\text { Italian } \\
\text { Society of } \\
\text { Anesthesia, } \\
\text { Analgesia, } \\
\text { Resus- } \\
\text { citation } \\
\text { and Inten- } \\
\text { sive Care } \\
\text { (SIAARTI) }\end{array}$ & $\begin{array}{l}\text { Expert } \\
\text { Panel Re- } \\
\text { port of the } \\
\text { Task Force } \\
\text { for Mass } \\
\text { Critical } \\
\text { Care and } \\
\text { the Ameri- } \\
\text { can College } \\
\text { of Chest } \\
\text { Physicians }\end{array}$ & $\begin{array}{l}\text { Several in- } \\
\text { tensive care } \\
\text { professional } \\
\text { associ- } \\
\text { ations/ } \\
\text { Academy } \\
\text { for Ethics } \\
\text { in Medicine } \\
\text { (AEM) }\end{array}$ & $\begin{array}{l}\text { Addressed } \\
\text { under gen- } \\
\text { eral rules } \\
\text { of medical } \\
\text { ethics }\end{array}$ & $\begin{array}{l}\text { No central- } \\
\text { ized guide- } \\
\text { lines }\end{array}$ \\
\hline Status & $\begin{array}{l}\text { Clinical } \\
\text { ethical } \\
\text { recommen- } \\
\text { dation }\end{array}$ & Guide & $\begin{array}{l}\text { Clinical } \\
\text { and ethical } \\
\text { recommen- } \\
\text { dations }\end{array}$ & $\begin{array}{l}\text { No specific } \\
\text { guidance }\end{array}$ & $\begin{array}{l}\text { No central } \\
\text { guidance }\end{array}$ \\
\hline $\begin{array}{l}\text { Maximizing } \\
\text { benefit }\end{array}$ & $\begin{array}{l}\text { Maximize } \\
\text { benefit for } \\
\text { the largest } \\
\text { number of } \\
\text { people }\end{array}$ & $\begin{array}{l}\text { Benefit to } \\
\text { the greatest } \\
\text { number } \\
\text { of people } \\
\text { Maintain } \\
\text { the func- } \\
\text { tion of the } \\
\text { healthcare } \\
\text { system }\end{array}$ & $\begin{array}{l}\text { As many } \\
\text { patients } \\
\text { as possible } \\
\text { to bene- } \\
\text { fit from } \\
\text { medical } \\
\text { care }\end{array}$ & $\begin{array}{l}\text { Case by } \\
\text { case assess- } \\
\text { ment }\end{array}$ & $\begin{array}{l}\text { Case by } \\
\text { case assess- } \\
\text { ment in the } \\
\text { hospital }\end{array}$ \\
\hline
\end{tabular}




\begin{tabular}{|c|c|c|c|c|}
\hline Equality & $\begin{array}{l}\text { All patients } \\
\text { (COVID } \\
\text { and non- } \\
\text { COVID } \\
\text { are treated } \\
\text { according } \\
\text { to same } \\
\text { criteria }\end{array}$ & $\begin{array}{l}\text { All current } \\
\text { and new } \\
\text { patients } \\
\text { presenting } \\
\text { with critical } \\
\text { illness }\end{array}$ & $\begin{array}{l}\text { All patients } \\
\text { who require } \\
\text { intensive } \\
\text { therapy } \\
\text { Social cri- } \\
\text { teria not } \\
\text { permissible }\end{array}$ & $\begin{array}{l}\text { All patients } \\
\text { are treated } \\
\text { according } \\
\text { to same } \\
\text { criteria }\end{array}$ \\
\hline Equity & - & $\begin{array}{l}\text { Equitably, } \\
\text { with no } \\
\text { preference } \\
\text { to any } \\
\text { particular } \\
\text { illness }\end{array}$ & $\begin{array}{l}\text { No discrim- } \\
\text { ination }\end{array}$ & $\begin{array}{l}\text { No discrim- } \\
\text { ination }\end{array}$ \\
\hline $\begin{array}{l}\text { Short- } \\
\text { term } \\
\text { survival }\end{array}$ & $\begin{array}{l}\text { Probability } \\
\text { of Survival }\end{array}$ & $\begin{array}{l}\text { Acute } \\
\text { illness Like- } \\
\text { lihood of } \\
\text { benefit }\end{array}$ & $\begin{array}{l}\text { Short-term } \\
\text { survival } \\
\text { prognos- } \\
\text { tic score } \\
\text { (SOFA) }\end{array}$ & $\begin{array}{l}\text { Medical } \\
\text { criteria as } \\
\text { assessed } \\
\text { by clinical } \\
\text { doctors }\end{array}$ \\
\hline $\begin{array}{l}\text { Long- } \\
\text { term } \\
\text { Survival }\end{array}$ & $\begin{array}{l}\text { Comorbidities } \\
\text { and func- } \\
\text { tional } \\
\text { status }\end{array}$ & $\begin{array}{l}\text { Comorbid } \\
\text { conditions } \\
\text { and acute } \\
\text { illness } \\
\text { using stan- } \\
\text { dardized } \\
\text { assessments }\end{array}$ & $\begin{array}{l}\text { Long-term } \\
\text { prognosis } \\
\text { Comorbidi- } \\
\text { ties General } \\
\text { frailty (clin- } \\
\text { ical frailty } \\
\text { scale) }\end{array}$ & $\begin{array}{l}\text { Medical } \\
\text { criteria as } \\
\text { assessed } \\
\text { by clinical } \\
\text { doctors }\end{array}$ \\
\hline Life-span & $\begin{array}{l}\text { Life ex- } \\
\text { pectancy } \\
\text { Age limit } \\
\text { "may ul- } \\
\text { timately } \\
\text { need to be } \\
\text { set" }\end{array}$ & $\begin{array}{l}\text { A system } \\
\text { based in } \\
\text { age alone, } \\
\ldots . \text {, does } \\
\text { not account } \\
\text { for differ- } \\
\text { ences in } \\
\text { baseline } \\
\text { mortality } \\
\text { risk be- } \\
\text { cause of } \\
\text { underlying } \\
\text { health }\end{array}$ & $\begin{array}{l}\text { No } \\
\text { (de)prioritizat } \\
\text { "solely be- } \\
\text { cause of } \\
\text { biological } \\
\text { age" }\end{array}$ & - \\
\hline
\end{tabular}




\begin{tabular}{|c|c|c|c|c|c|}
\hline $\begin{array}{l}\text { Additional } \\
\text { criteria }\end{array}$ & $\begin{array}{l}\text { Proportionali } \\
\text { of care; No } \\
\text { "first come } \\
\text { first serve }\end{array}$ & $\begin{array}{l}\text { tPrioritize } \\
\text { key groups } \\
\text { (e.g. staff, } \\
\text { research } \\
\text { volun- } \\
\text { teers, chil- } \\
\text { dren and } \\
\text { pregnant } \\
\text { women) } \\
\text { avoid lot- } \\
\text { tery and } \\
\text { "first come } \\
\text { first served" }\end{array}$ & - & - & - \\
\hline Source & \begin{tabular}{|l|} 
Vergano \\
et al. 2020 \\
\end{tabular} & $\begin{array}{l}\text { Maves et al. } \\
2020\end{array}$ & \begin{tabular}{|l|} 
Marckmann \\
et al. 2020
\end{tabular} & $\begin{array}{l}\text { Polish Min- } \\
\text { istry of } \\
\text { Health, De- } \\
\text { partment } \\
\text { of Public } \\
\text { Health } \\
\text { Correspon- } \\
\text { dence of } 18 \\
\text { February } \\
\text { 2021. Pol } \\
\text { and }\end{array}$ & $\begin{array}{l}\text { Brazil } \\
\text { Ministry } \\
\text { of Health } \\
\text { freedom of } \\
\text { information } \\
\text { query }\end{array}$ \\
\hline
\end{tabular}

Table 1: Guidelines for triage decisions in the countries under study, adopted from Jöbges et al. 2020.

The guidelines and recommendations have implications for the attributes of the conjoint experiment. We summarize the implications in terms of expected effects of prioritizing a patient over another in Table 2. We leave out Brazil as from the available information it is not possible to formulate such expectations.

In Germany, Poland, the USA, and Italy we expect a positive effect of the chance of survival. For Poland, Germany this is the only criterion attribute that should matter according to the guidelines. In Italy age can have an additional effect on prioritization, as an age limit is discussed explicitly in the guidelines. In the USA guidelines, the job and age can have an additional impact on triage decisions. Most important none of the guidelines allow partisanship to play a role in the decision of how ICU Beds are allocated. But also the other attributes are not considered as part of the guidelines, such as gender, the time of arrival, and if a patient has children. 
Italy

Job

Effect is not expected. Not -

mentioned.

Gender

Effect is not expected. Not -

mentioned.

Children

Effect is not expected. Not mentioned.

Chance of Survival A positive effect is expected. "The underlying principle Those with higher chance of would be to save limited survival will be advantaged. resources which may become extremely scarce for those who have a much greater probability of survival and life expectancy" (p.471)

Time of Arrival Effect is not expected. Not mentioned.

Age A negative effect is expected. Age limits are recommended to be set in worst cases. The older a patient, the less likely to be chosen for ICU

Partisanship Effect is not expected. Due to the amount of people included in the decision, it becomes less likely that there will be an effect of partisanship.

"An age limit for the admission to the ICU may ultimately need to be set" (p. 471)

"The decision to withhold or withdraw life-sustaining treatments must always be discussed and shared among the healthcare staff, the patients and their proxies" (p.471) 
USA

Job

Gender

Children

Chance of Survival

Time of Arrival

Age

Partisanship

Germany
Effect is expected. Job attributes should have a positive effect as long as the jobs are associated with essential and key services in the context of the Corona pandemic.

Effect is not expected. Not mentioned.

Effect is not expected. Not mentioned.

Effect is expected. People less likely to survive are also less likely to get ICU. People with too high survival chance also do not get ICU.

Effect is not expected.

Positive effect is expected.

Effect is not expected. Transparency requirement is expected prevent decisions making on grounds other than medical attributes.
"Communities may choose to prioritize to key groups, to include health-care workers (HCWs), first responders, research volunteers, or others who are either perceived as risking their own safety for the public's benefit or who have a special role in pandemic response" (p.217)

"We must recognize that patients less likely to benefit from critical care may not be provided those services" (p.217) However, too fit and healthy patients are excluded in the ICU allocation as well. Likelihood is based on SOFA score (p.218)

First-come-first-served should be avoided (p.217)

"Children $[\ldots]$ receive special priority in other schema, with the concept of saving not only the most lives but also the greatest number of years of life" (p.217)

"Patients who do not receive critical care because of a triage system must be supported, and the rationale for medical decision-making must be clearly communicated to them or their family members" 
Job

Gender

Children

Chance of Survival

Time of Arrival

Age

Partisanship
Effect is not expected.

Effect is not expected.

Effect is not expected. Not mentioned.

Positive effect is expected. The higher the success of ICU, the higher the likelihood of being chosen for ICU.

Effect is not expected.

Effect is not expected. It is forbidden to consider it as a variable in the decisionmaking process.

Effect is not expected. The amount of responsible people makes it unlikely that partisanship have a significant effect. It would also be hard to measure partisanship of a patient, since the recommendation includes a list of indicators to consider during the arrival of patients
"According to German constitutional law, human lives must not be weighed against other human lives." (p.116) "According to German constitutional law, human lives must not be weighed against other human lives." (p.116)

"[... overall assessment should consider all important factors influencing the prospect of success (current illness, commodities, general health status). [...] This assessment also serves as the basis for any prioritization which may be necessary" (p.119)

"According to the principle of equality, prioritization Are not permitted on the basis of calendar age, social characteristics, or specific underlying illnesses or disabilities."

"Therefore, whenever possible, the decisions should be made according to the multiple-eyes principle" (p.116) 


\section{Poland}

Job

Gender

Children

Chance of Survival

Age

Partisanship
Effect is not expected.

Effect is not expected.

Effect is not expected.

Positive effect is expected.

The higher the success of ICU, the higher the likelihood of being chosen for ICU.

Time of Arrival Effect is not expected.

Effect is not expected

Effect is not expected. As decisions are left to clinicians and other doctors taking care of patients, there are no procedural safeguards, but the guidance provided to doctors require them to only take into account the medical assessment of the patients.
"Ordinary guidelines only focus on medical assessment of patient's health needs and available treatment methods made individually for each medical case." Correspondence with the Polish Ministry of Health, 19 February 2021

Same as above.

Same as above.

Centrality of medical assessment of patients' health needs.

Centrality of medical assessment of patients' health needs.

Centrality of medical assessment of patients' health needs.

Same as above.

Table 2: Expected effects form the medical guidelines for the attributes of the conjoint experiment. 


\subsection{Political Parties}

This section provides more detail on the party selection in the five countries. A vast share of the literature in on affective polarization focuses on the United States, where the central partisan divide is unequivocally between Republicans and Democrats. In multi-party contexts, the divide is more difficult to define in terms of single parties. For our study, we choose two parties that represent distinct ideological political camps. We first discuss the general left-right positions of the parties, afterwards discussing the COVID-lockdown positions of the parties.

\subsubsection{General Left-Right Positions}

In general, we select parties that are on the left and right of the political spectrum and that play a crucial role in the political debates during the field period. Figure 5 shows political positions from the Manifesto Project's RILE index Volkens et al., 2020, Krause et al. 2020] for parties who gained more than $5 \%$ in the last available election before the field period. For comparison, the United States shows a clear divide between the republican and democratic party in the 2016 presidential election on the RILE index. In Poland we work with the Law and Justice Party (PiS) and the Civic Platform (PO) that in the 2015 parliamentary election advocated the most extreme positions in their manifestos. In Italy we pick Italia Viva, Matteo Renzi's new party, and the right-wing League of Matteo Salvini. In the 2018 elections Matteo Renzi was head of the center-left coalition lead by the Democratic Party. The RILE index for the League is more moderate compared to Go Italy of Silvio Berlusconi, but the Leagues success in the election and its restrictive stances on immigration make it a more ideal candidate for our experiment. In Germany, we choose the right-wing populist Alternative for Germany (AfD) and the Alliance90'/Greens. While the Left-party holds more left values on the RILE index, the Greens are perceived as the general opponent to the Afd on cultural dimension. In Brazil we choose the parties of the two presidential candidates Lula (PSL/Aliança ) and Bolsonaro (PSL/Aliança) of the 2018 election. The rile index of the election campaigns of Lula "The People happy again" and Bolsonaro "Brazil above everything, god above everyone" shows clearly opposing camps.

\subsubsection{COVID Lockdown Positions}

The positions of the parties regarding lockdown measures are of further interest to our project. In each country, we conduct a small online media analysis to define positions on COVID lockdown measures for the left and right party of the conjoint experiment. Table 3 provides a summary. 


\begin{tabular}{lll}
\hline Party & $\begin{array}{l}\text { Lock-down } \\
\text { Position }\end{array}$ & Comment \\
\hline
\end{tabular}

\section{US}

Democrat In favor

In general democrat politicians are mostly in favor for stricter rules but Biden is more careful with new lockdown measures. On local level, politicians are stricter.

Opposed Cunningham, 2020, dw., 2021, Brownstein, 2020, Ward, 2020, Gold, 2020, Stracqualursi 2020

Republican Opposed Most of Republicans are opposing strict measures, also on the local level. The last 5 states that did not impose shutdowns were Republican.

\section{Germany}

Alliance In favor The greens are generally in fa90/The Greens vor for strict measures. Boris Palmer, a local green politician, is one of the few green politicians who publicly opposes stricter meaOpposed Vogel et al. 2020, Ward, 2020, Zeleny, 2020, Wingerter and Hindi, 2020, Woodward, 2020 sures. However, the position about school closing is disputed.

AfD

Opposed In their corona position paper 2020 they claim that everything should be able to open again, thus they oppose new Support Ismar, 2021, bil, 2021, Gediehn, 2021, die, 2021, 2020. zei, 2020b; Opposed |bil, 2021, die, 2021 shutdowns in general.

\section{Brazil}


PT (Lula) In favor

PSL/Allianca Opposed (Bolsonaro)

\section{Poland}

PO

In favor

PiS

In favor

\section{Italy}

Italia Viva In favor
The position of the $\mathrm{PT}$ is not really salient when it comes to pandemic restrictions. However, there we found one interview in which Lula speaks out for stricter measures.

Bolsonaro clearly opposes strict measures and participated in anti-shutdown protests. He dismissed two of his health ministers in a short time which were in favor of shutdowns.
Support not, 2020, the, 2020

\begin{tabular}{|c|c|c|}
\hline \multirow{2}{*}{\multicolumn{3}{|c|}{$\begin{array}{l}\text { Opposed Watson, } \\
\text { 2020, Mello and Gaier }\end{array}$}} \\
\hline & & \\
\hline & Charner, & 2020 . \\
\hline & & \\
\hline
\end{tabular}
2020, Mello and Gaier, dw. 2021, bbc, 2020

Support Matraszek 2020, Zalewski, 2020. icize the strict measures. The most salient topic, however, was that the presidential election was not postponed and that many claim that PiS uses Corona pandemic to increase their power.

The PiS and their prime minister are in favor of strict measures and imposed a shutdown when there were only 26 cases. Also in late December they

Opposed Barteczko and Florkiewicz, 2020, Support Mailonline, 2020, reu, 2020?

supported a new shutdown.

Since Italia Viva was part Opposed Vagnoni, of the government coalition, they apparently did not op2020, Santamaria, 2020. pose the shutdown. However, in one interview Matteo Renzi claims that the country should reopen again. 


\begin{tabular}{|c|c|c|c|}
\hline Lega & In favor & $\begin{array}{l}\text { The leader of the Lega, Salvini } \\
\text { supports strict measures and } \\
\text { early asserted that shutdowns } \\
\text { are necessary. }\end{array}$ & 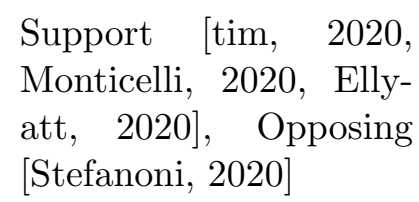 \\
\hline
\end{tabular}

Table 3: Party positions about lockdown measures for left and right parties in the conjoint experiment. 


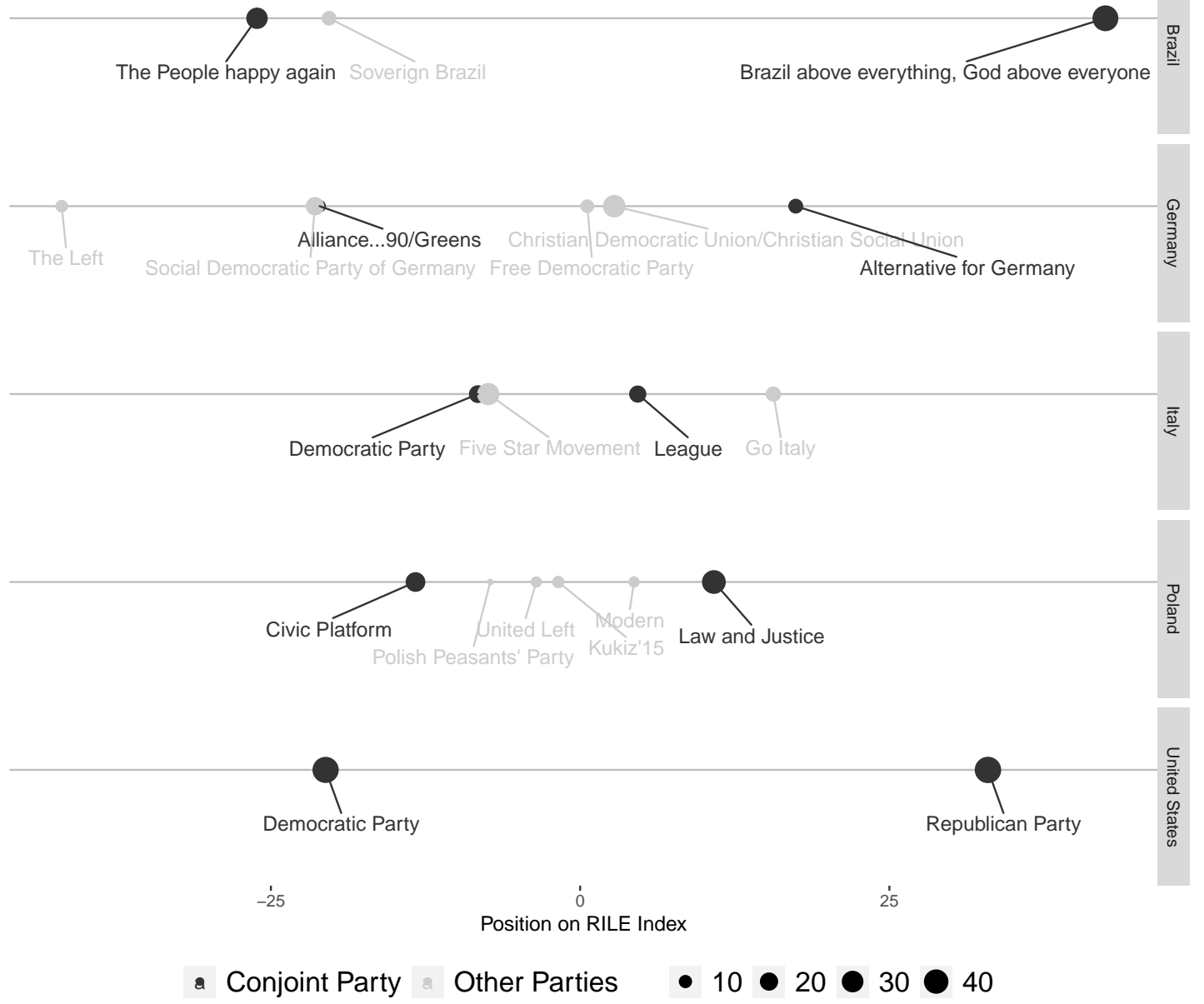

Figure 5: Party positions of left and right parties using the RILE index. The partisan labels used in the conjoint experiment are highlighted in black. The size of the points represents the vote share of the parties in the last general election. 


\section{Sample Information}

\subsection{Quota}

We used quota samples based on Age Groups, Education, and Gender in the five countries. Table 1 provides information about the quotas and the actual shares in our surveys. For some of the categories we see small discrepancies to reach the sample size. E.g. in Brazil we slightly over sample Low Education groups (Quota $56 \%$ actual share in survey $31 \%$ ) at the dispense of high and middle education groups. We do not expect the discrepancies to bias estimates of the main analysis.

Table 4: Quota and survey shares in different countries

\begin{tabular}{lcc}
\hline Variable & Share Survey & Quota \\
\hline Brazil & & \\
Age 18-29 & 0.25 & 0.35 \\
Age 30-39 & 0.25 & 0.24 \\
Age 40-49 & 0.24 & 0.19 \\
Age 50-59 & 0.12 & 0.12 \\
Age 60-75 & 0.13 & 0.10 \\
Education High & 0.22 & 0.12 \\
Education Low & 0.31 & 0.56 \\
Education Middle & 0.47 & 0.32 \\
Female & 0.48 & 0.51 \\
Male & 0.48 & 0.49 \\
& & \\
Germany & & \\
Age 18-29 & 0.15 & 0.18 \\
Age 30-39 & 0.19 & 0.16 \\
Age 40-49 & 0.19 & 0.17 \\
Age 50-59 & 0.23 & 0.21 \\
Age 60-75 & 0.24 & 0.28 \\
Education High & 0.39 & 0.35 \\
Education Low & 0.23 & 0.33 \\
Education Middle & 0.38 & 0.32 \\
Female & 0.49 & 0.51 \\
Male & 0.49 & 0.49 \\
& & \\
Italy & & \\
Age 18-29 & 0.14 & 0.17 \\
Age 30-39 & 0.16 & 0.16 \\
Age 40-49 & 0.21 & 0.20 \\
& &
\end{tabular}


Age 50-59

$\begin{array}{ll}0.21 & 0.22\end{array}$

Age 60-75

$0.28 \quad 0.26$

Education High

$0.20 \quad 0.18$

Education Low

$\begin{array}{ll}0.33 & 0.38\end{array}$

Education Middle

$\begin{array}{ll}0.38 & 0.42\end{array}$

Female

$0.46 \quad 0.51$

Male

$0.46 \quad 0.49$

\section{Poland}

Age 18-29

$\begin{array}{ll}0.18 & 0.19\end{array}$

Age 30-39

$0.21 \quad 0.21$

Age 40-49

$0.20 \quad 0.19$

Age 50-59

$0.16 \quad 0.16$

Age 60-75

$0.25 \quad 0.24$

Education High

$0.39 \quad 0.24$

Education Low

$0.05 \quad 0.42$

Education Middle

$0.56 \quad 0.34$

Female

$0.49 \quad 0.52$

Male

$0.49 \quad 0.48$

USA

Age 18-29

Age 30-39

$\begin{array}{ll}0.20 & 0.22\end{array}$

Age 40-49

$0.19 \quad 0.19$

Age 50-59

$0.18 \quad 0.18$

$0.19 \quad 0.19$

Age 60-75

$\begin{array}{ll}0.23 & 0.23\end{array}$

Education High

$0.41 \quad 0.43$

Education Low

$\begin{array}{ll}0.37 & 0.39\end{array}$

Education Middle

$0.22 \quad 0.18$

Female

$0.47 \quad 0.51$

Male

0.47

0.49 


\subsection{Attention Check}

\begin{tabular}{lr}
\hline Country & Passed Attention Check \\
\hline Brazil & 0.66 \\
Germany & 0.59 \\
Italy & 0.60 \\
Poland & 0.57 \\
USA & 0.55 \\
\hline
\end{tabular}

Table 5: Percentage of respondents who pass the attention check in different countries

The survey includes a question to evaluate if respondents read and understand the note on each of the the four conjoint decisions (See Figure 2). "Thinking back on the previous questions: Which of the following people do you think has a higher chance of survival after intensive medical care?" The answering options are "An 80-year-old man with a $40 \%$ chance of survival after the use of intensive care measures", "A 40-year-old man with a $40 \%$ chance of survival after using intensive care measures", and "Both have the same chance of survival"

The table reveals that around $60 \%$ in the different country samples correctly answer "both have the same chance of survival". Part of the respondents, hence, potentially still consider age and gender as contributing to the survival chance, calling for caution when interpreting the effects. To probe the consequences of this, we re-estimate the models among respondents who pass the attention and understanding check (see section 5.7). 


\section{Descriptive Statistics}

\subsection{Job Relevance Perception}

Respondents rate the system relevance of the job categories similarly across countries. Figure 6 shows that most respondents name doctors and nurses as very essential, followed by police officers. There is variation regarding the perceived relevance of professors, otherwise the ordering is quite stable across the countries under study.
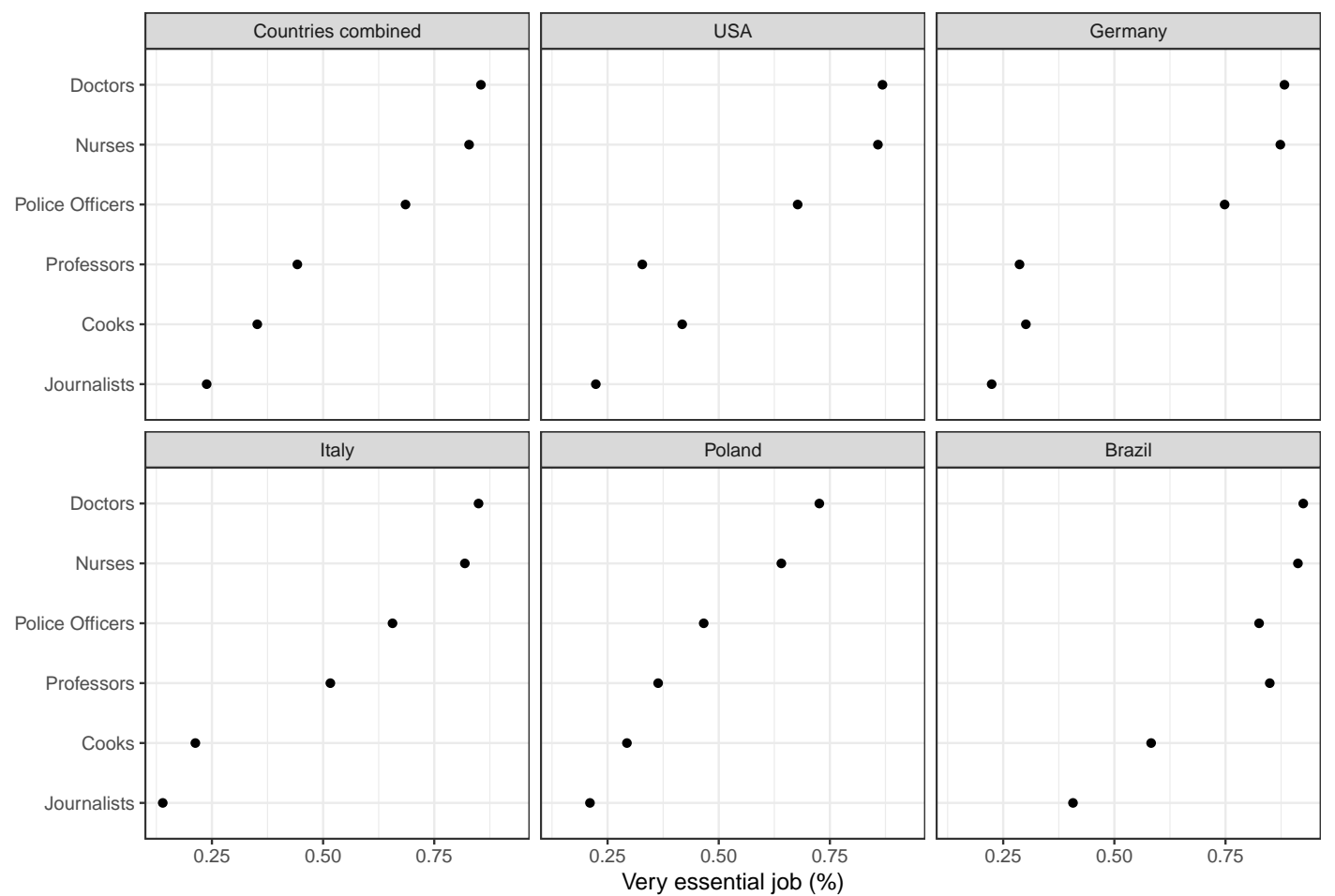

Figure 6: Perceived job relevance in countries under study. Figure shows percent that indicate that a job is very essential. 


\subsection{Affective Polarization}

The distribution of affective polarization between the country specific parties in our study varies over the different contexts. Figure 7 shows the affective polarization measure, as the difference in rating scores, between the left and the right party. In Germany with with small right party, the measures is tilted against the right parties. In the other countries the measure distributes around zero. The figure further highlights the fixed cut point of -5 and +5 that are used to define left and right affectivly polarized respondents in the main text.

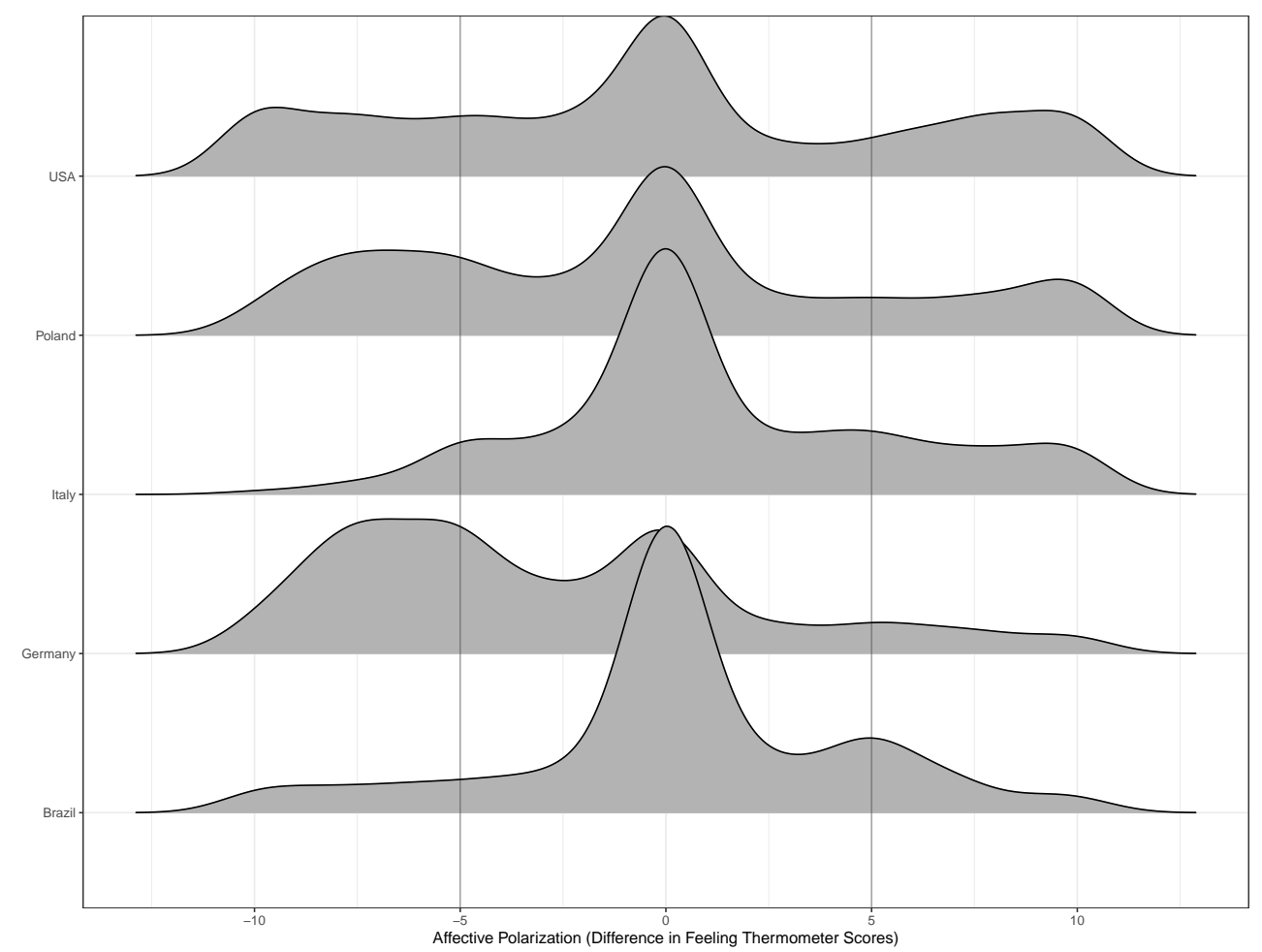

Figure 7: Distribution of affective polarization measure in different countries. Party rating score of the right party minus party feeling rating score of the left party 


\subsection{Experience with COVID}

The respondents in the countries differ in respect to their experience with COVID infections. Figure 8 shows that especially in Brazil respondents knew people that have been infected with COVID. Only 20\% reported that they do not know a person infected with COVID. In the U.S. sample around $40 \%$ say that they know one to three persons. In Italy around $30 \%$ knew one to three persons who were infected. The numbers are lower for Germany and Poland, where up to $80 \%$ in our sample did not know an infected person.

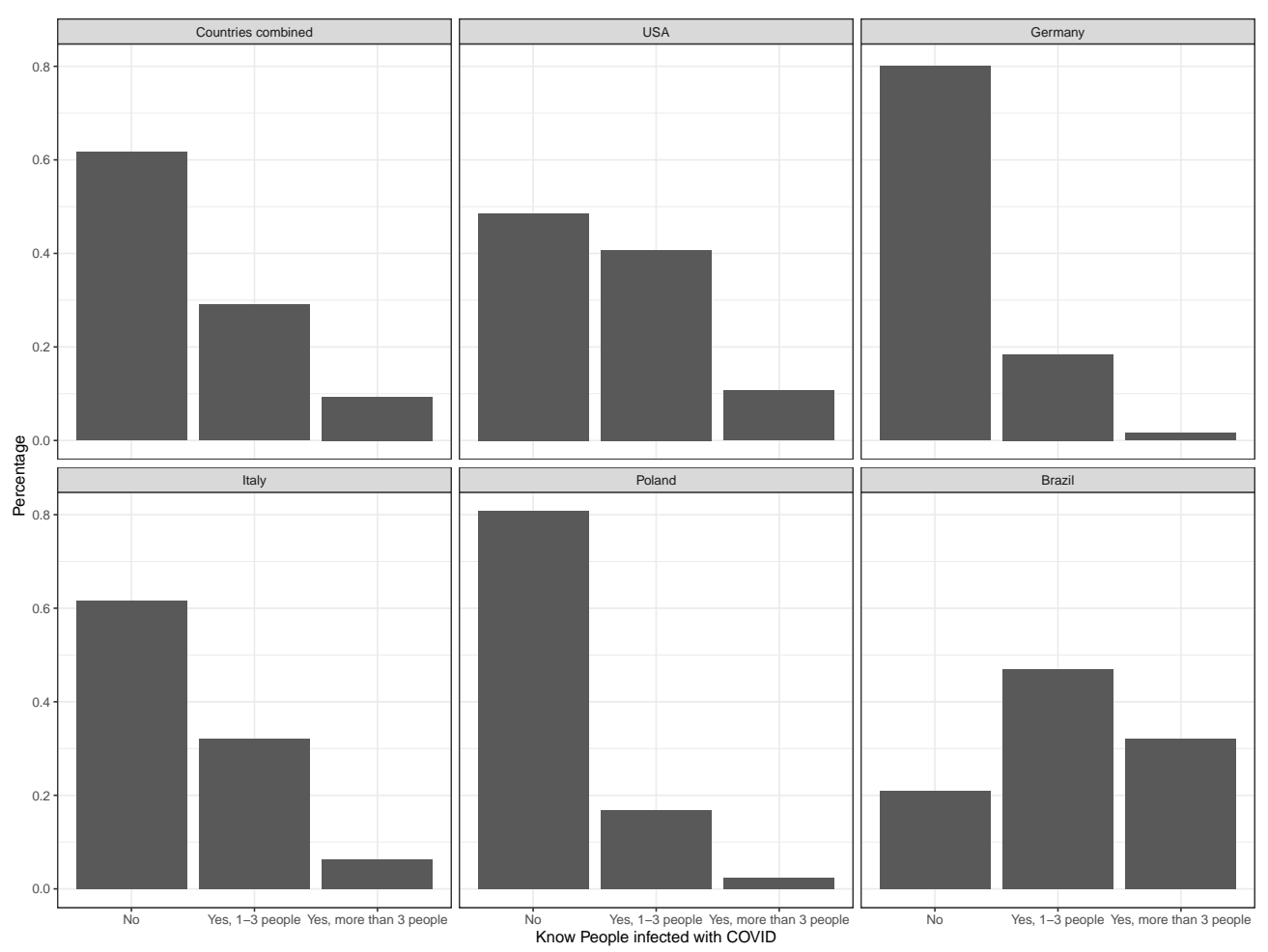

Figure 8: Experience with COVID. Percentage of respondents who know of anyone who has been infected by COVID-19 in different countries. 


\subsection{Compliance and risk behavior}

The survey further includes items about compliance and risk behavior. To analyze the compliance with corona recommendations (keep a distance; wash hands frequently; wear masks if keeping a distance is not possible) of different partisan groups in comparison, we plot the proportion of partisans who state that they always comply from the left and right party in Figure 9. The percentage who always comply with recommendations differs between partisan groups and countries. In the USA we observe that Republicans on average only comply with $70 \%$ and Democrats with around $87 \%$. The same holds for Germany, where right partisans are far less likely to state that they always comply with corona recommendations. The pattern that right partisans comply less is not reflected in our data for the other countries. In Italy, we observe no clear difference (also due to the small share of Italy Viva supporters). In Poland partisans from the left and right party comply at equal rates and more often than non-partisans. In Brazil, right partisans state that they comply at higher rates.

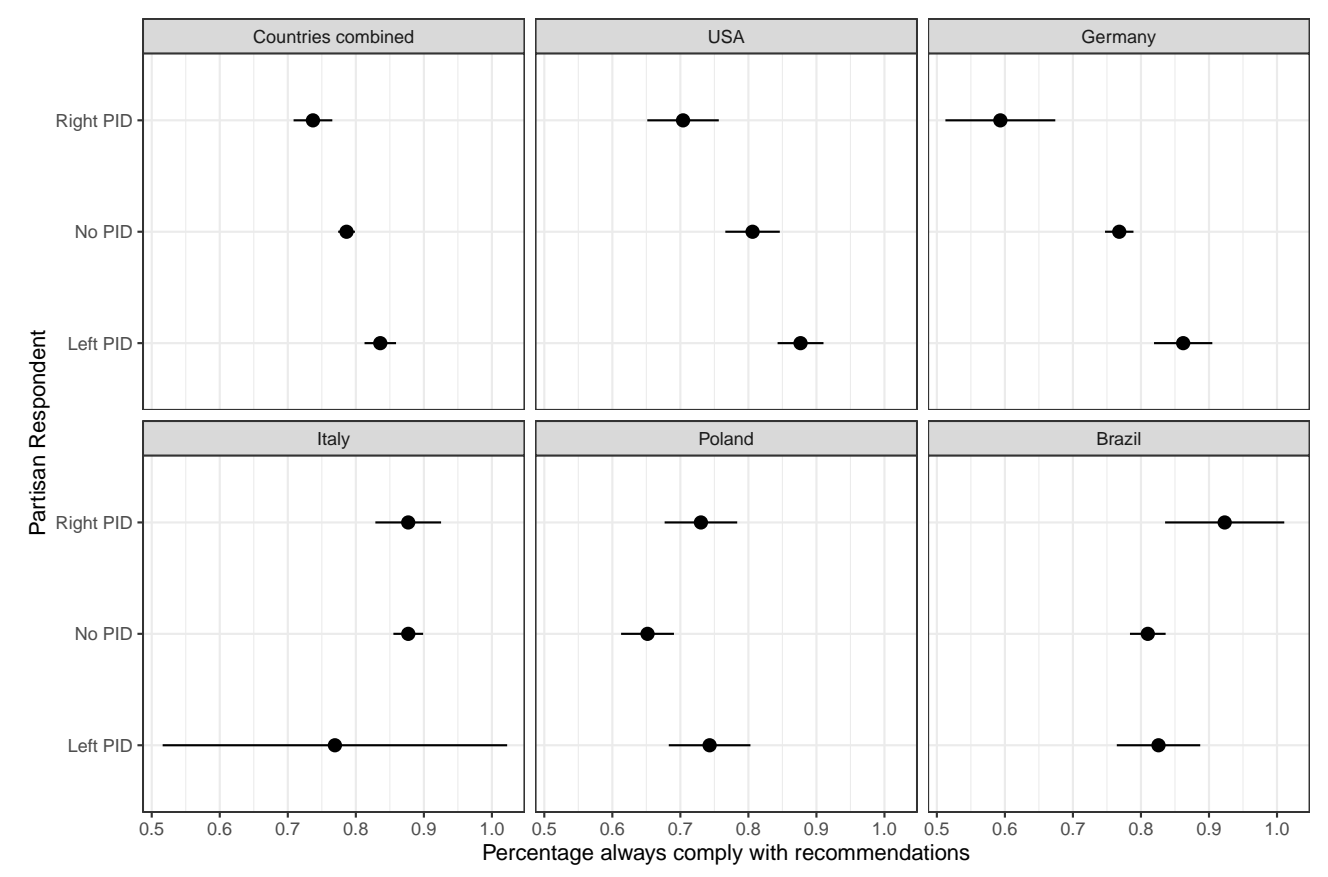

Figure 9: Compliance with health recommendations. Percentage of respondents who always comply with recommendations for partisanship groups and countries.

We further plot the reported risk behavior across Partisan groups in Figure 10. We form an index from three items that ask how often respondents engage in risk behavior (Met with friends, relatives, or acquaintances in person; Visited a restaurant, café, or bar; 
Used public transport). The figure shows a similar pattern compared to the compliance behavior. In Germany and the US, right partisans also admit to slightly more risky behavior. In the other countries, their right partisans are not more clearly engaging in risky behavior. Only in Brazil, the results counter the tendency we observed with the compliance question. Right partisans seem to slightly more frequently in risk behavior.

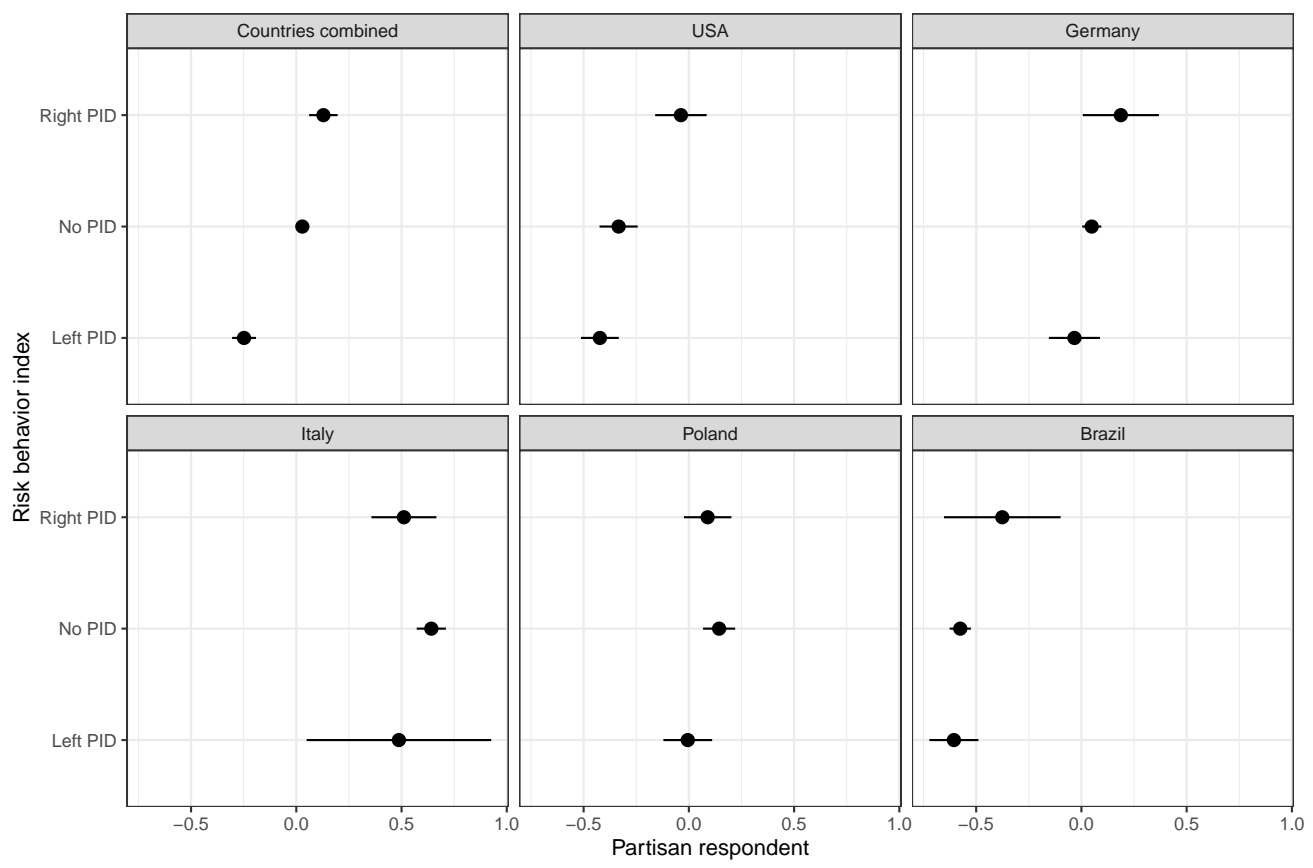

Figure 10: Risk behavior. Distribution of risk behvior index for partisanship groups and countries. Index contains three items: meet with friends, visit restaurants, use public. 


\section{Additional Analysis}

In this section, we describe additional results from the conjoint analysis. Some of the additional results are part of the pre-registered analysis (5.4, 5.6, and 5.5). Other parts of the additional results are included because of suggestions and reviewer points we received on the paper 5.25 .3 ,? 5.7 , and 5.9 .

\subsection{Average marginal component effects}

Next to the marginal means in the main text, we can present the average marginal component effects on prioritizing a patient with a certain attribute. The results are reported in Figure 11 and give insights in the extend of the effects.

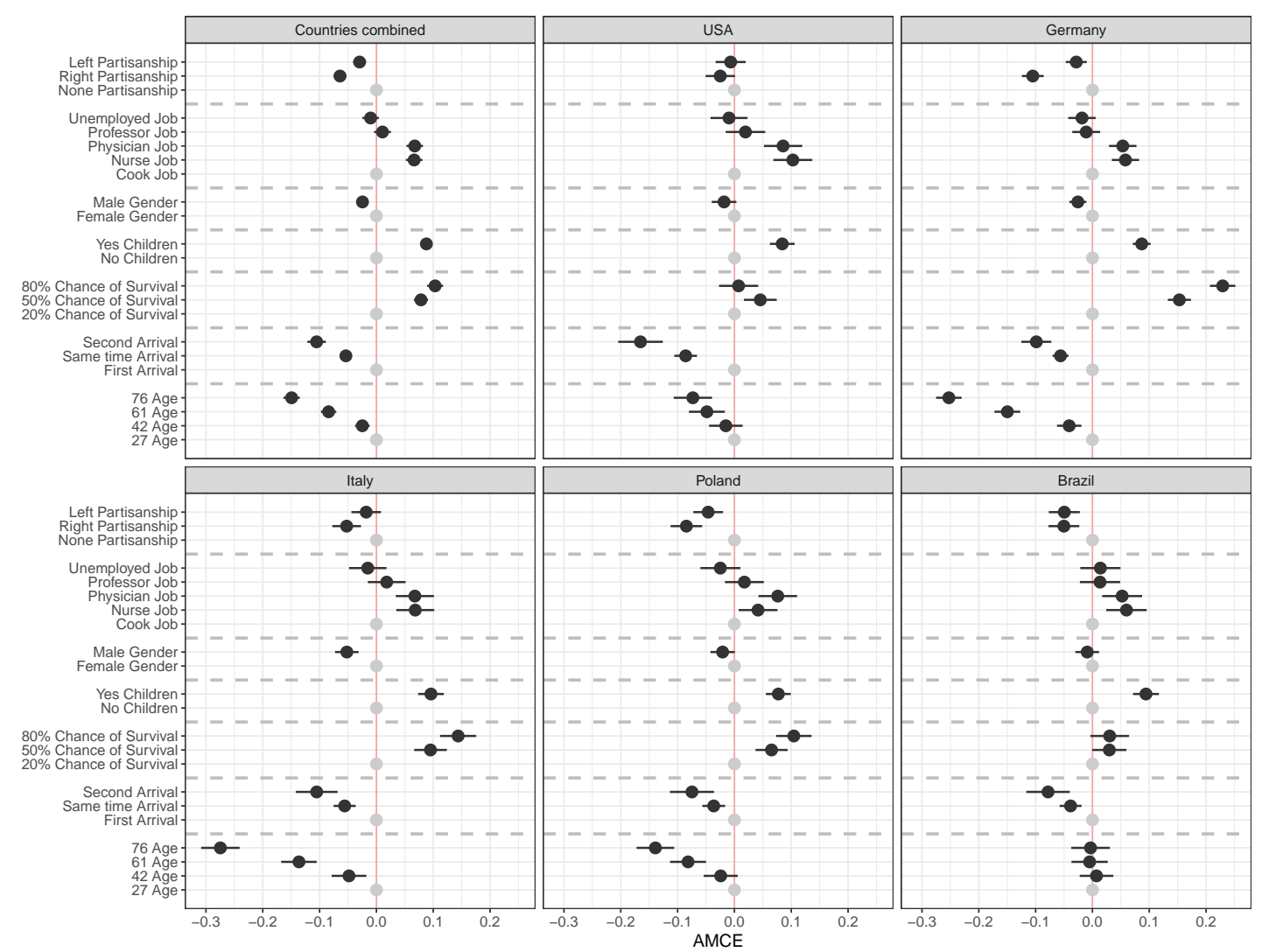

Figure 11: Average Marginal Component Effects of triage patient attributes in paired conjoint experiment. For all countries combined, USA, Germany, Italy, Poland and Brazil.

In all countries combined we estimate that respondents are around 3\%-pts. less likely to prioritize left-partisan patients and $6 \%$-pts less likely to prioritize right-partisan pa- 
tients compared to none-partisans. The partisan effects vary over the countries. The effects further highlight the relevance of features that are found in the medical guidelines, such as the chance of survival. Respondents prioritize patients with a high chance of survival (80\%) 10\%-pts more compared to patients with a low chance of survival (20\%). Age also matters a great deal: Respondents are $15 \%$-pts. less likely to prioritize a 76 year old patient compared to a young patient.

\subsection{Marginal Means conditional on Affective Polarization}

This section presents the marginal means conditional on affective polarization. While the main text presents the average marginal component interaction effects between left/right partisan patients, here we show the marginal means for all type of patients. Figure 12 shows the same pattern of out-party animus among left and right affectivly polarized respondents and in-party favourtism for right respondents.

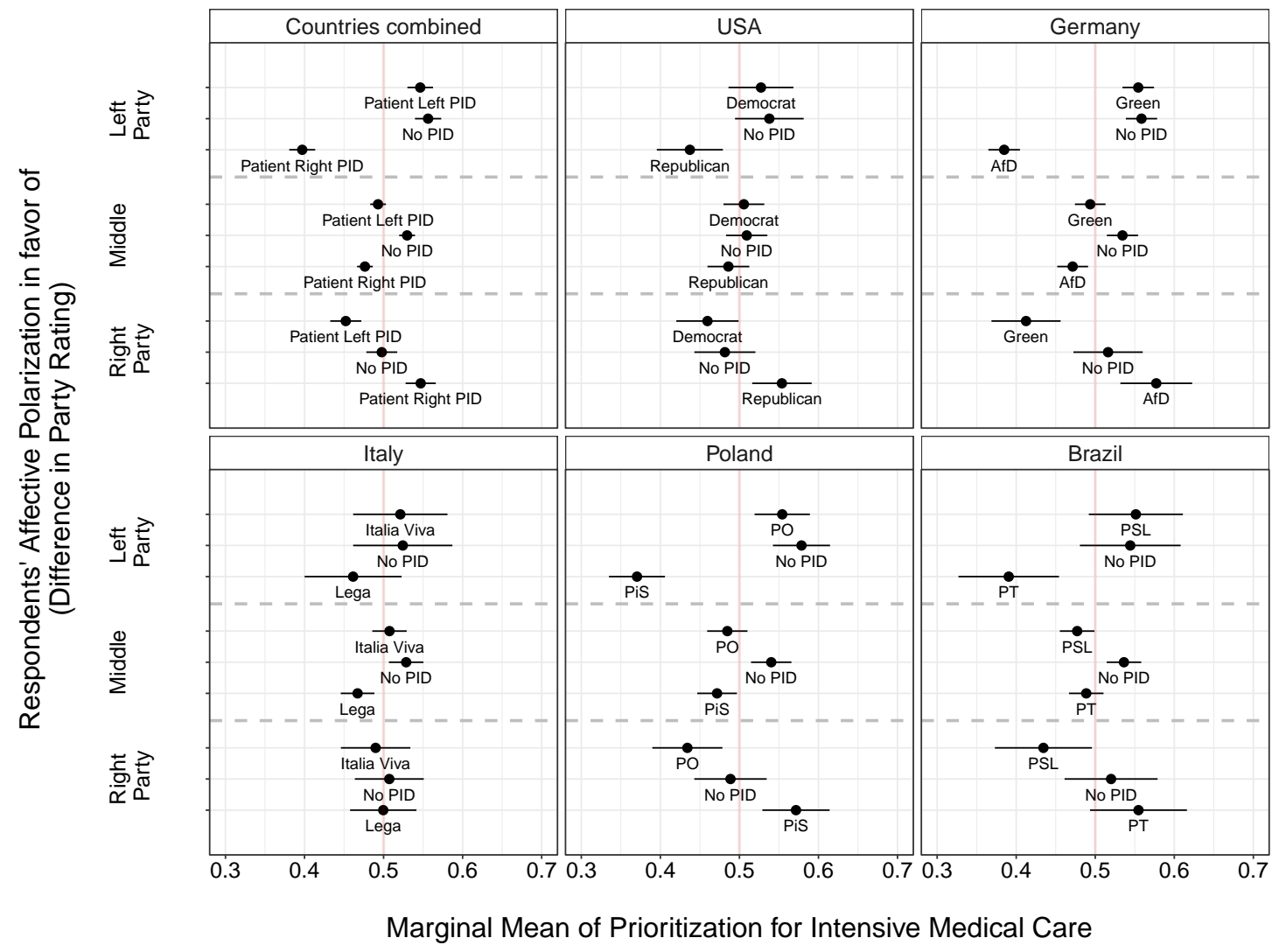

Figure 12: Marginal Means for Affective Polarization of triage patient attributes in paired conjoint experiment. For all countries combined, USA, Germany, Italy, Poland and Brazil. 


\subsection{Average Marginal Component Interaction Effect Affective Polarization (Percentiles)}

This section presents ACMIE for affective polarization measure, but using $33 \%$ and $66 \%$ percentiles instead of fixed cut-offs at -5 and +5 to define left and right affectively polarized respondents. Figure 13 shows that results are quite comparable. We identify out-party animus among left and right affectively polarized respondents. Only the ingroup favouritism effect of right respondents is not as pronounced. With the alternative coding in many contexts, we code more respondents as right affectively polarized, although they do not show strong differences in rating scores between the left and right party (as Figure 14 shows). This probably waters down the in-party favouritism effect that we identify with the main text cut-points measure and with the partisanship of the respondents (seeSM 5.5).

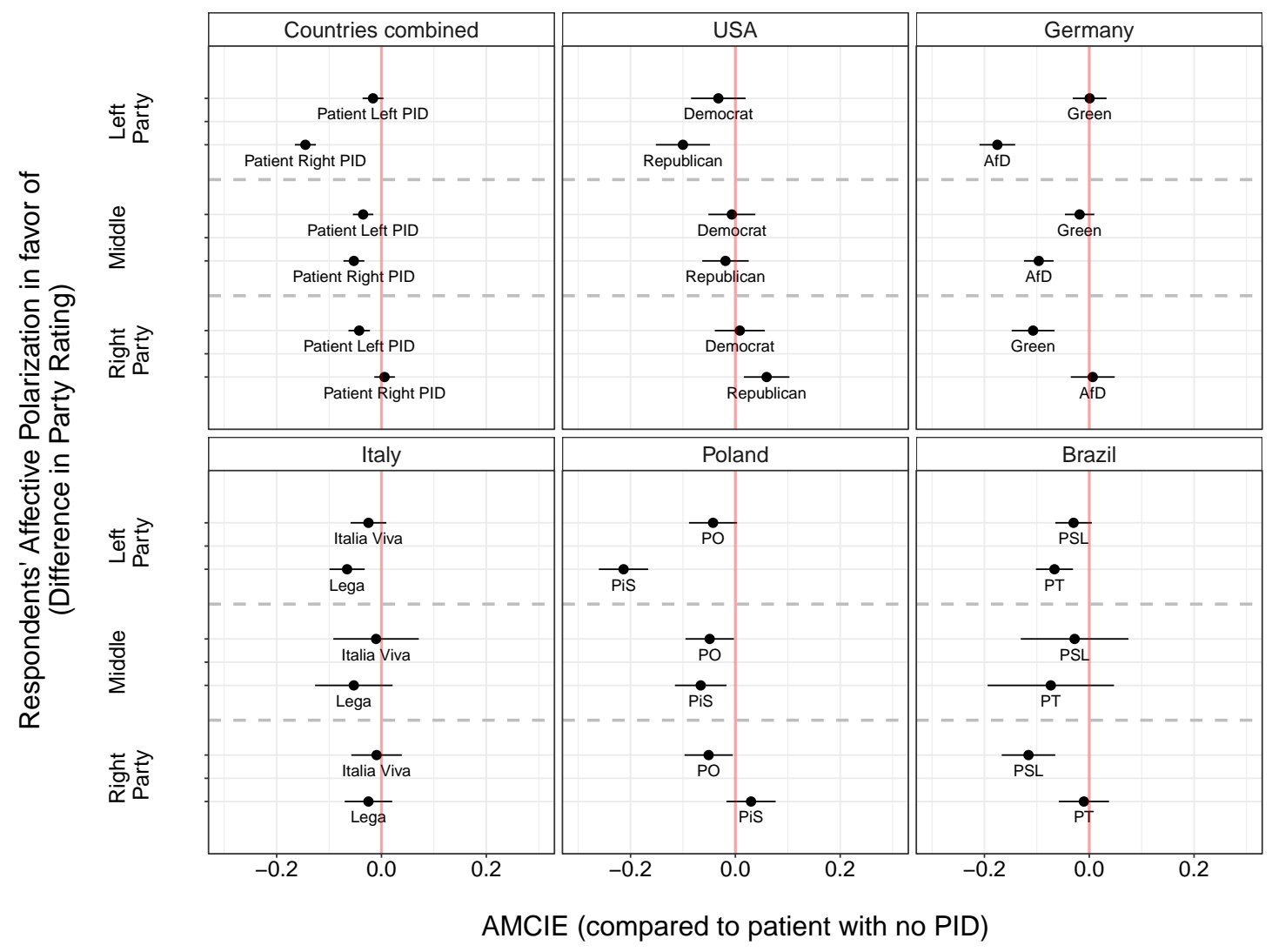

Figure 13: Average Marginal Component Interaction Affective for Affective Polarization of triage patient attributes in paired conjoint experiment. For all countries combined, USA, Germany, Italy, Poland and Brazil. 


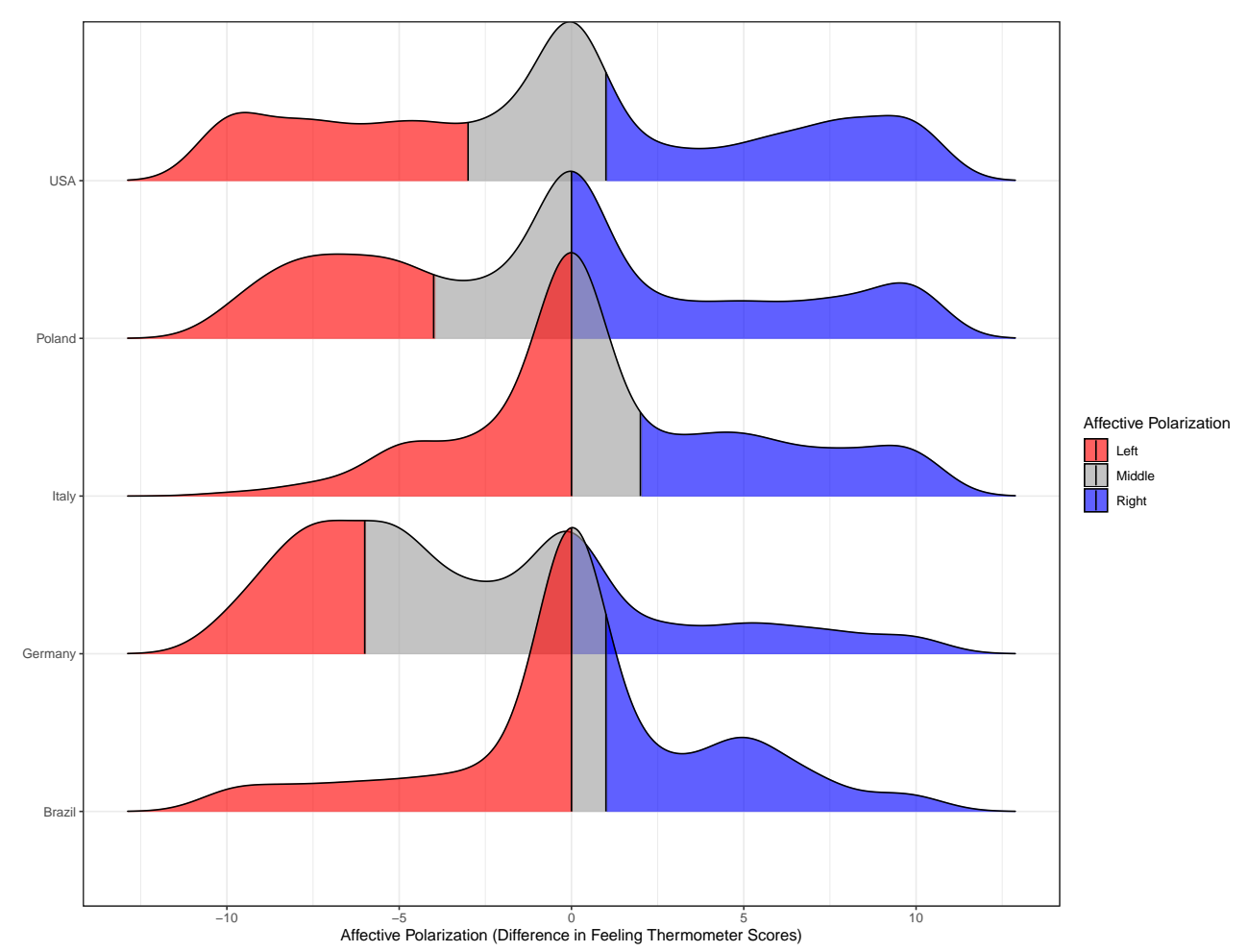

Figure 14: Distribution of affective polarization measure in different countries. Party rating score of the right party minus party feeling rating score of the left party. Shows 33\%- and $66 \%$ percentiles used as alternative cut-points.

\subsection{Average Marginal Component Interaction Effect for Sociodemographics}

The pre-analysis plan (6) contains additional conditional hypotheses (H8a-H8c). The hypotheses expect: older (younger) respondents to prefer older (younger) patients (H8a), male (female) respondents to prefer male (female) patients (H8b); and respondents with children to prefer patients with children $(\mathrm{H} 8 \mathrm{c})$. In this section, we report on the results using the Average Marginal Interaction effects of the respective patient attributes with respondent covariates.

Figure 15 shows the estimates of the interaction effects and reveals no consistent support for the hypotheses over the countries. In the US the children interaction effect is significantly different from zero (4.7\%-pts., a p-value below 0.05$)$. This implies that respondents with children are even more likely to prefer patients with children $(11.4 \%$ pts increase if the respondent has children, compared to a $6.7 \%$-pts. increase if the respondent does not have children). In the other countries, we find no clear interaction effect. In the US and Brazil, male respondents are also more likely to choose male 


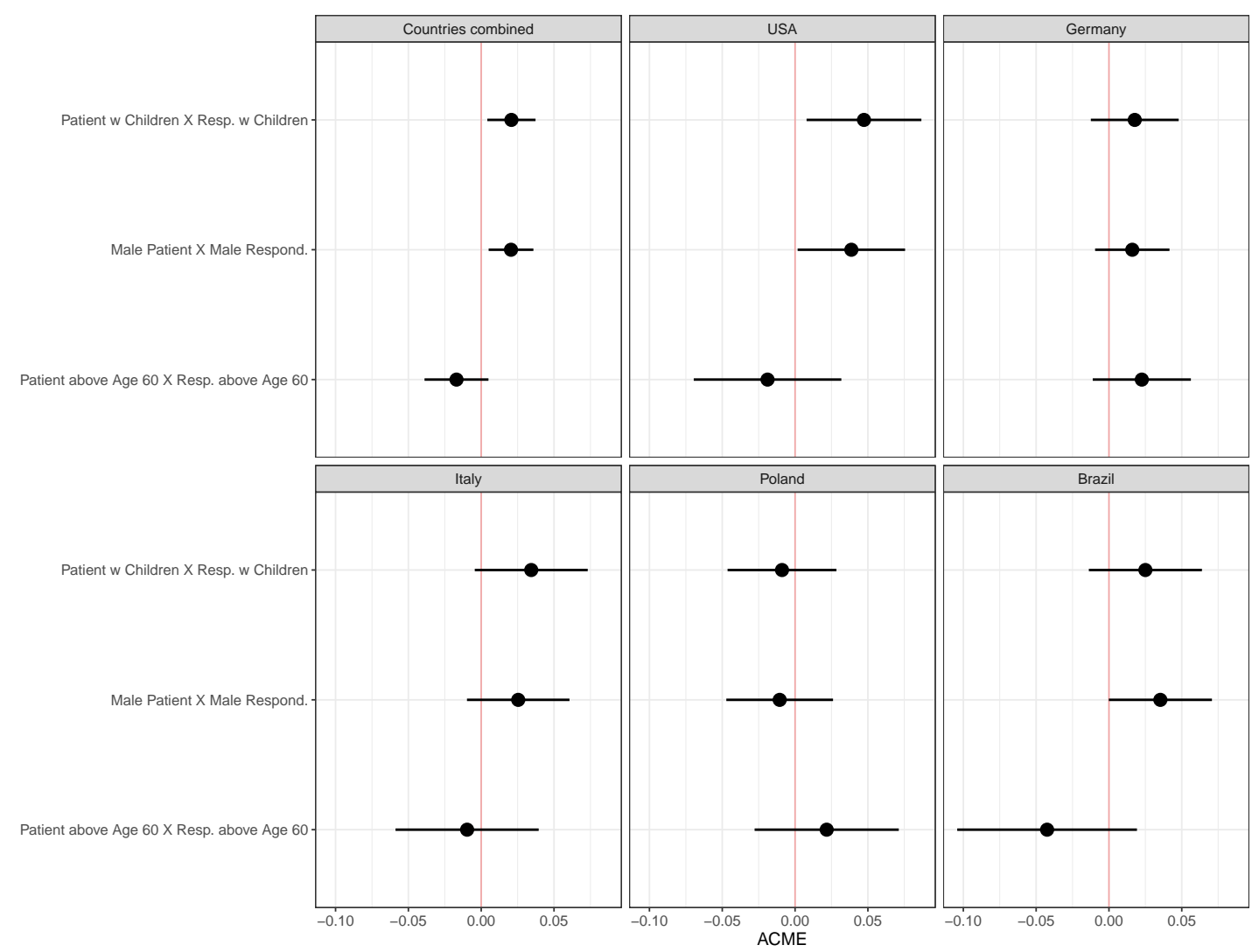

Figure 15: Attribute level importance

patients (3.9\%-pts. in the US and $3.5 \%$-pts. in Brazil). Combining this with the direct effect shows that female respondents slightly downgrade male respondents in the US (-3.7\%-pts.), but male respondents' prioritizing is not affected by the gender of the patient. There is no clear support for this hypothesis in the other countries. We find no support for the Age hypothesis in any of the countries. When we combine all countries this yields support for the hypothesis that priories differ based on gender and children of the respondent.

\subsection{Average Marginal Interaction Component Effect Partisanship}

The pre-analysis plan (Section 6) further expects a conditional effect of a patient's partisan orientation based on the partisanship of the respondents (H8d). "Respondents with a partisan affiliation prefer patients with the same or ideologically similar partisan affiliation over patients with an ideologically dissimilar partisan affiliation." We test the hypothesis using the partisanship identity of the respondents, coding a one if the re- 
spondents identify with the right or left party in the different countries 1 The analysis is similar to the main analysis based on rating differences between the two parties, except that we only consider the conditional effects among partisan identifiers.

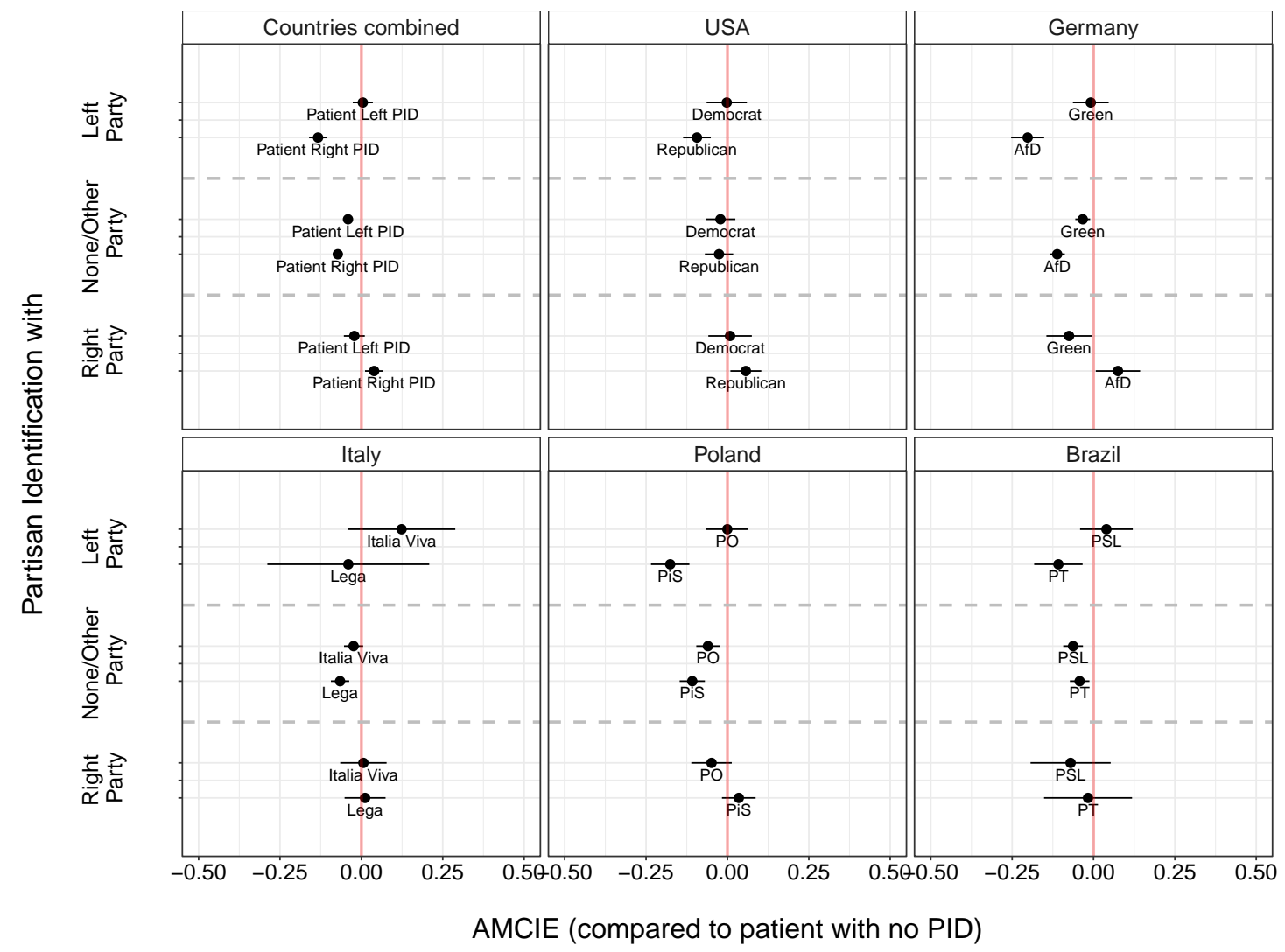

Figure 16: Average Marginal Interaction Component Effect of patients' party affiliation with partisanship of respondent in paired conjoint experiment. For all countries combined, USA, Germany, Italy, Poland and Brazil.

The results are reported in Figure 16, reveal similar patterns compared to the analysis based on the affective polarization scores. In the combined country sample, left partisan respondents downgrade right partisans. This pattern exists in the USA, Germany, Poland, and Brazil. In Italy, the number of Italia Viva partisans is too small to estimate precise effects. We also estimate a small positive effect among respondents with right partisanship in prioritizing a right party patient. This indication of in-group favoritism is present in the USA and Germany. Interestingly, the effects for patients with left partisan alignment are not as strongly moderated by partisanship. E.g. in the US, neither

\footnotetext{
${ }^{1}$ The corresponding survey question follows the standard three-step question format in the US and a two-step question format in the other countries (see Section 1.3 .
} 
democratic nor republican respondents treat patients with a democratic affiliation differently compared to patients without an affiliation. This pattern holds in most of the contexts and shows that non-political consequences seem to focus on the right rather than left patients' partisanship.

\subsection{Average Marginal Interaction Component Effect with Linear Interaction Effect}

The pre-analysis plan specifies a linear interaction effect between the affective polarization (rating scale difference between two parties) and the partisan attribute of the patient.

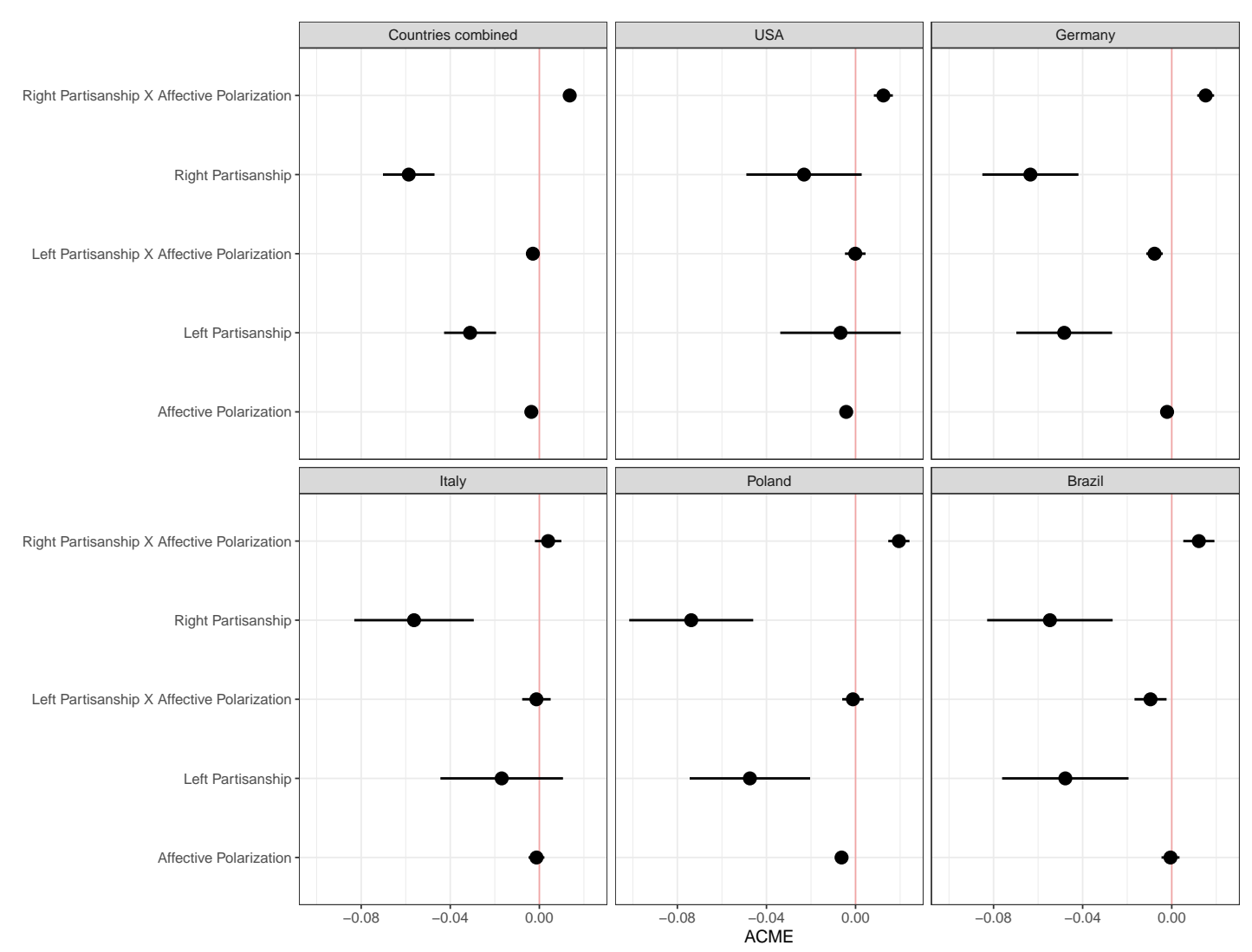

Figure 17: Average Marginal Interaction Component Effect of patients' party affiliation with partisanship of respondent in paired conjoint experiment. For all countries combined, USA, Germany, Italy, Poland and Brazil.

Figure 17 outlines that the parameter estimates with a linear interaction model lead to the same conclusions. We generally find positive interaction effects for the affective 
polarization measure with a right affiliation of a patient. This implies that more negative affective polarization measures (which indicate higher rating scores for left parties), further decrease the negative effect on the right partisan affiliation of the patient. This general pattern is present in all country contexts except for Italy. It differs slightly to the extent to which patients with equal rating scores (affective polarization equal to zero) downgrade patients with partisan affiliation. In the US, for patients with zero affective polarization, we estimate no significant effect of democratic or republican affiliation compared to a non-partisan patient. But we do for the other countries. The interaction effects are again not as strong for left patients. Here we only estimate significant negative interaction effects in Germany and Brazil that are smaller, compared to the interaction effects we observe for a partisan patient.

\subsection{Evaluating Effects among Respondents who Pass the Attention Check}

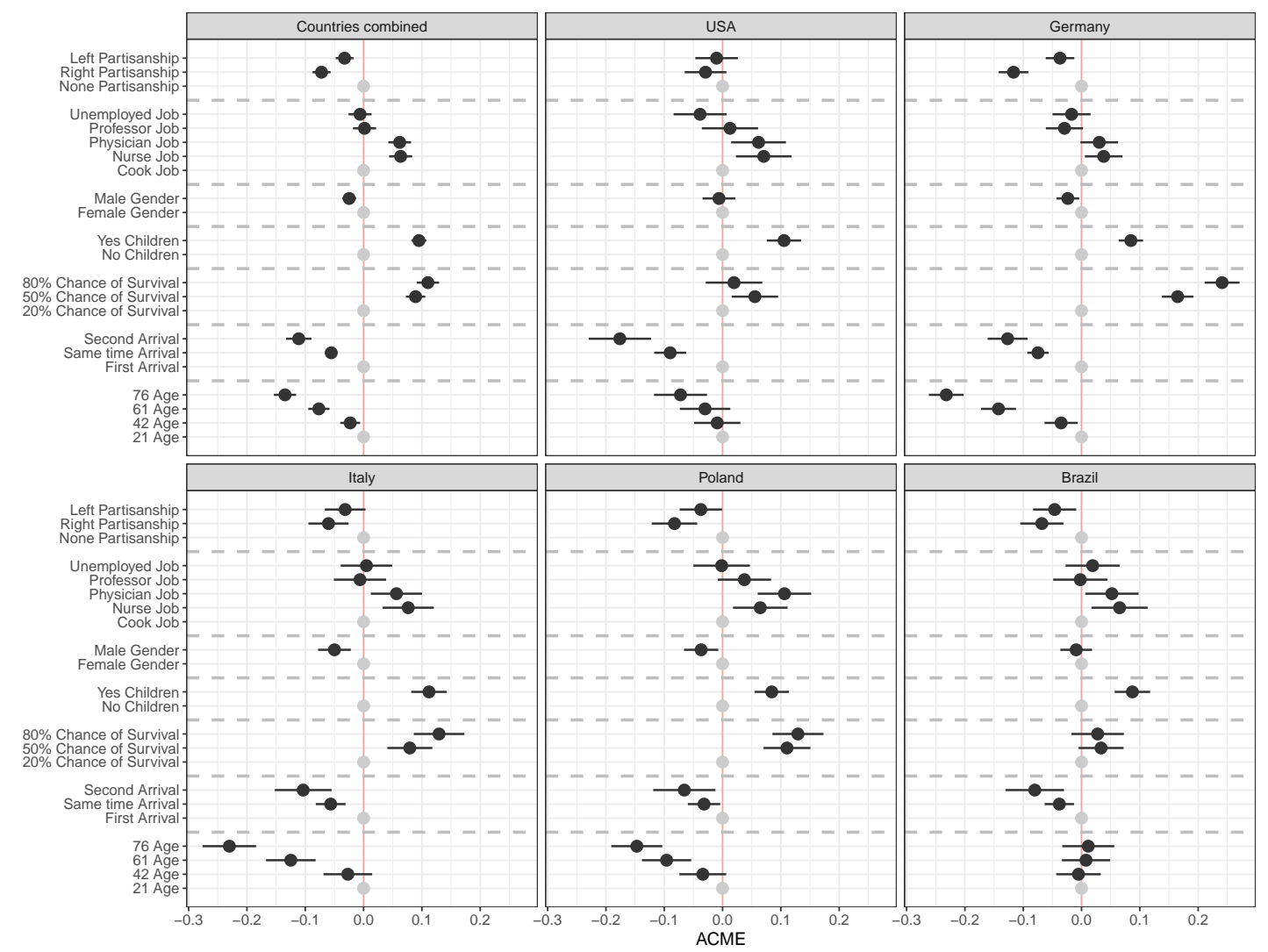

Figure 18: Average Marginal Component Effects of triage patient attributes in paired conjoint experiment when excluding respondents who do not pass the attention check. 
This section reports on the results when excluding respondents who do not pass the attention check in our survey (see Section 5.7). The effect estimates are almost unchanged compared to the analysis of the full sample, as Figure 18. The estimation uncertainty increases due to the around $40 \%$ smaller sample.

\subsection{Evaluating Attribute Importance from Open Survey Answers}

This section describes the procedure for analyzing the content of the open question: "What characteristics of a patient would be most important to you in deciding who should have access to intensive care first? Note: You can name characteristics mentioned in the questions just answered as well as other characteristics."

The content of open responses was analyzed using two custom dictionaries containing words and phrases in the following categories. (Note that these are not directionallycoded, so that if 'age' is matched this may indicate that younger or older patients should be preferred): age (any mention of an age, age range, or age cohort) remaining_life, survival_chance (how likely the patient is to survive the triage process), race, party, children, family, sex (male or female), education (level of education), poverty, job (job type), system_relevance (the societal importance of the patient's job), nationality, health (the patient's previous state of health), arrival_order (whether a patient came in before, after, or at the same time as another), and prev_condition.

Two dictionaries with these categories were developed, one for the German responses and one in English to be applied to the US responses and machine translations of the other country responses. Each dictionary were developed from complete vocabulary lists from each country's responses which should maximize coverage, and checked using random keyword-in-context evaluations. There were sufficiently few mentions of party that the evaluation of the importance or unimportance of party affiliation were handcoded after the dictionary analysis.

Figure 19 show the distribution of responses by country with party responses marked in red. Table 6 shows that of those who responded, only between $1.1 \%$ and $2.5 \%$ mentioned party and Figure 20 shows that a majority of these mentions emphasized that party should not matter to triage decisions. From hand coding the German data we also find that 7 of the 25 responses noting the importance of party single out the AfD, presumably as being particularly unworthy e.g. "All the AfD voters are facists". However, the number of responses is very small and interpreting the intent of the respondent requires interpretation, so these observations should not be over-interpreted. 


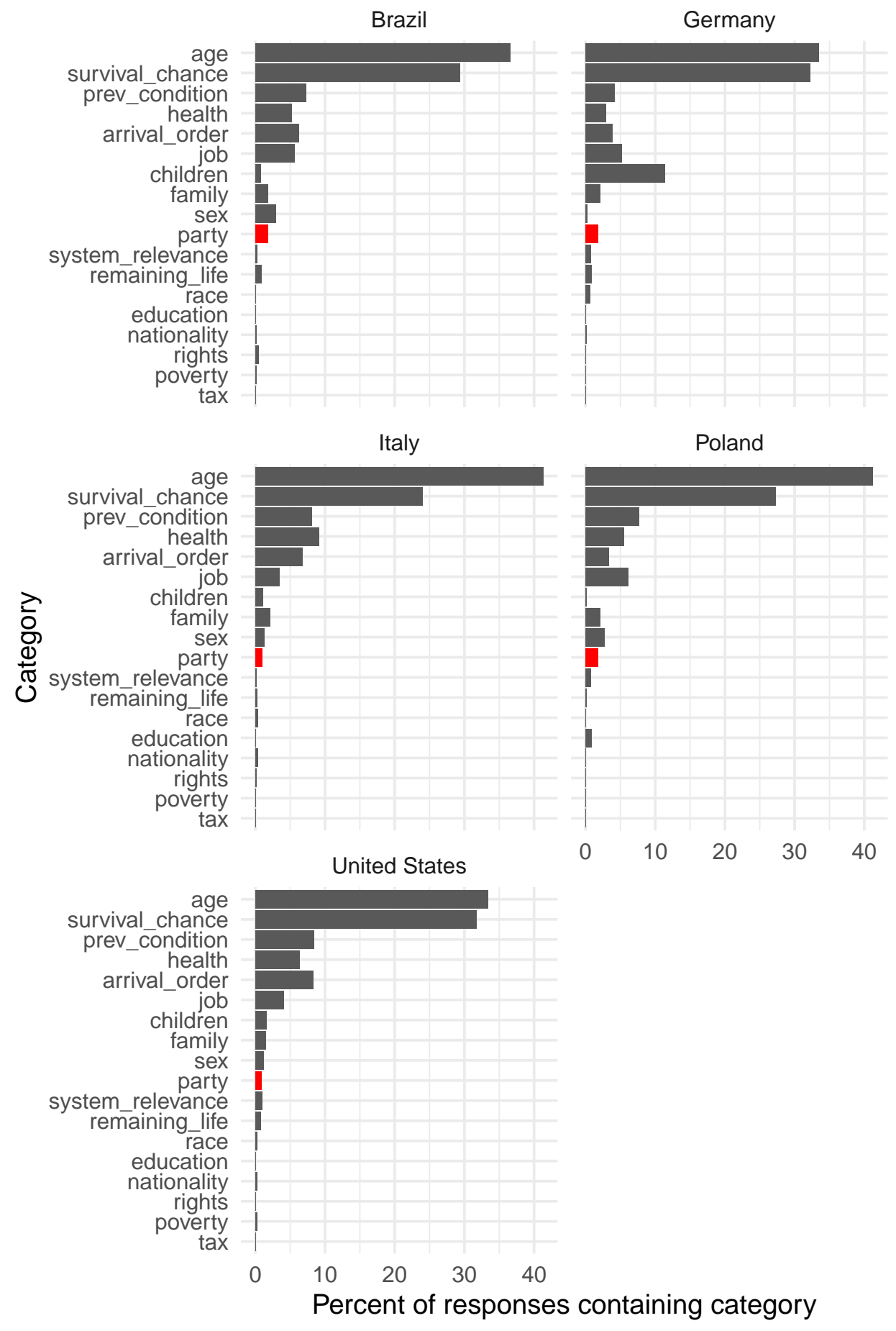

Figure 19: Topic matches in each country's open responses. Percentage of responses that mention party shown in red. Note: open response may match more than one category. 
Table 6: Open question response breakdown. Responses are shown in counts and as a percentage of respondents, and mentions of party affiliation are shown as counts and as a percentage of responses.

\begin{tabular}{rlcccc}
\hline & Germany & U.S.A. & Italy & Poland & Brazil \\
\hline Respondents & 2044 & 1078 & 1103 & 1097 & 1093 \\
Responses (\%) & $1802(88.2)$ & $1001(92.9)$ & $870(78.9)$ & $954(87)$ & $838(76.7)$ \\
Party (\%) & $45(2.5)$ & $12(1.2)$ & $10(1.1)$ & $21(2.2)$ & $18(2.1)$ \\
\hline
\end{tabular}

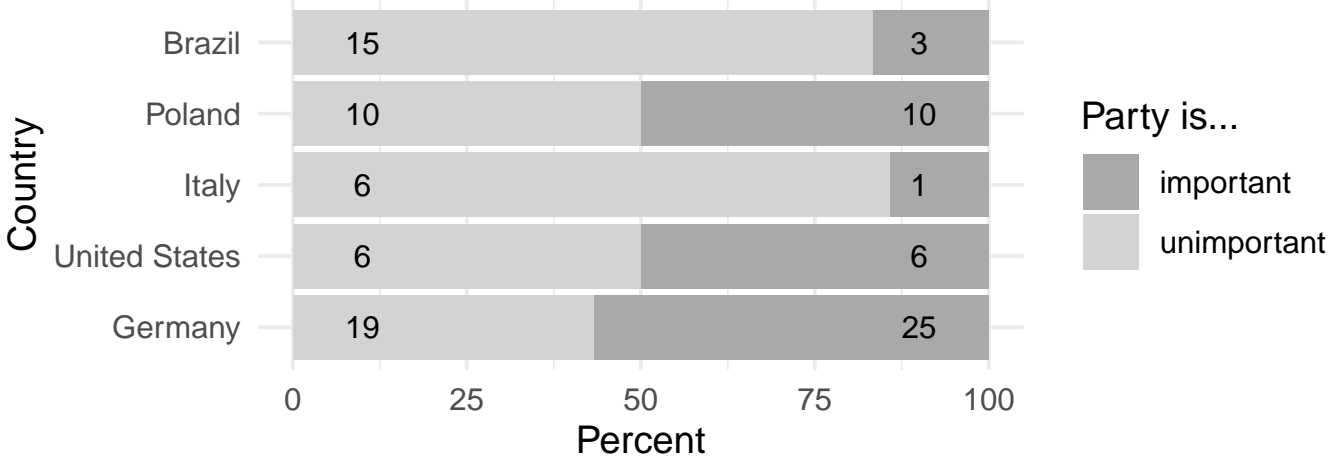

Figure 20: Proportion of respondents who said party affiliation was important vs unimportant. Actual number of responses in each category shown numerically. 


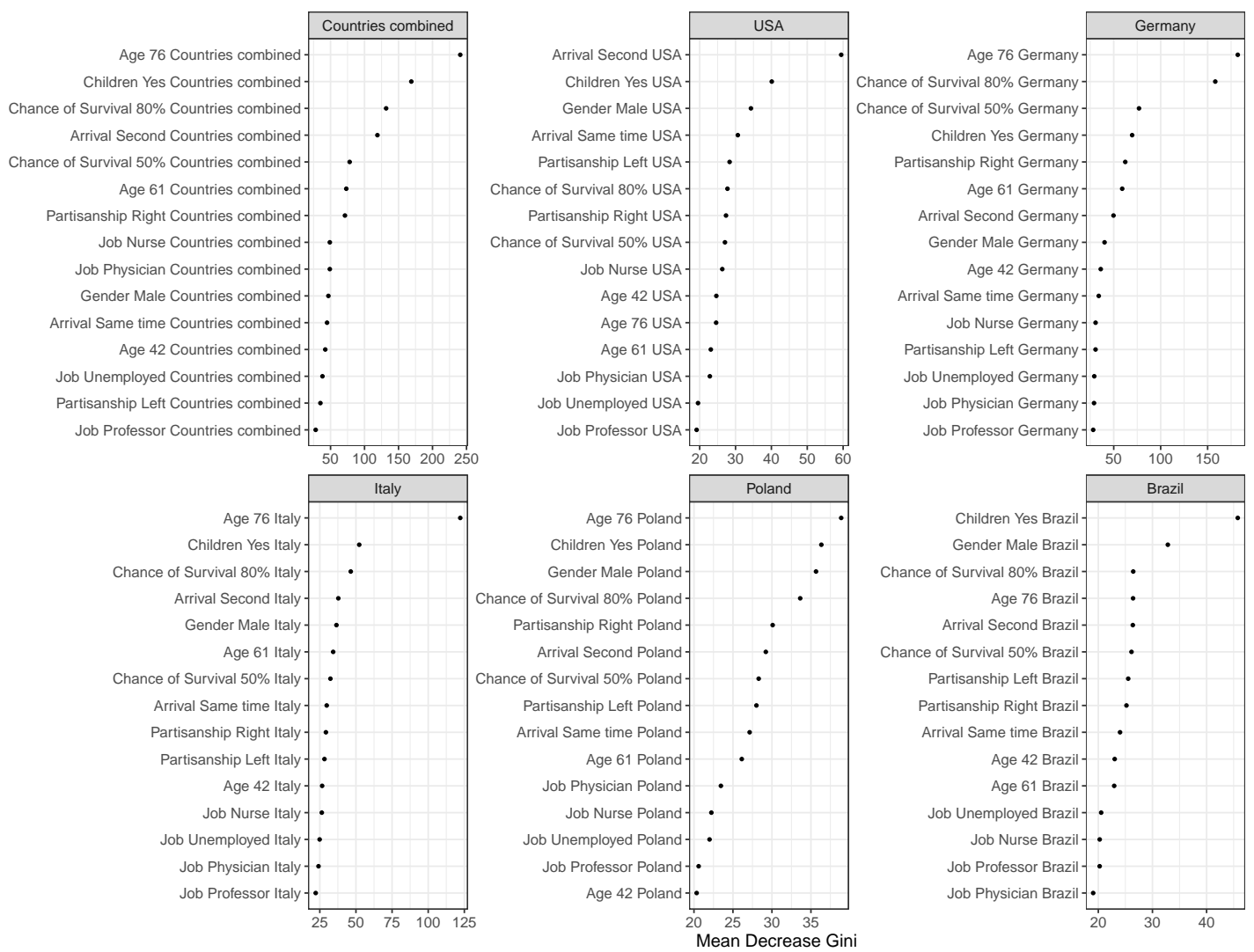

Figure 21: Attribute level importance

\subsection{Evaluating Attribute Importance using Random Forests}

To probe the importance of different features in respondents decision process, we report on the results of the variable importance if we employ random forests to model the decision process. As an ensemble of decision trees we can analyse the contribution of different variables to the model fit when variables are included in the forest. We use the mean reduction in the GINI as our measure of variable importance. It measures the gains of purity by splits of a given variable. If the variable is useful, it tends to split the patient correctly in being prioritized or not.

Figure 5.9 shows the results and confirms the importance of attributes such as Age, Children, and Chance of Survival in the combined country sample. Right partisanship of the Patient is more important compared to left partisanship, but both are generally found lower in the variable importance list. The Results vary slightly for the different country samples. In the US, arrival at the hospital is of central importance. In Germany, Italy, and Poland it is the old age of the Patient. In Brazil, children and gender seem to 
play an important role in this analysis. In none of the countries, partisanship is found among the top three variable importance. 


\section{Pre-Analysis Plan}

We pre-registered the study prior to data collection on August 12, 2020 at https:// osf.io/sv9ck. For the review process the supplementary material include an anonymized version of the pre-analysis plan in the next section.

\subsection{Anonymized Pre-Analysis Plan}




\section{Preregistration plan for:}

Citizen Preferences in a Fundamental Rights Dilemma:

Evidence from a Triage Experiment in Five Countries

Study Information

Design Plan

Sampling Plan

Variables

Analysis Plan

Other 


\section{Study Information}

\section{Title}

Citizen Preferences in a Fundamental Rights Dilemma: Evidence from a Triage Experiment

\section{Authors}

\section{Description}

We implement a paired conjoint with forced choice experiment to elicit citizen preferences in the moral dilemma of triage decisions. The experiment is framed in the context of the looming consequences of the COVID-19 pandemic on resource allocation in hospitals. We aim to identify (a) key heuristics applied in the population to make these ethically difficult choices, (b) how they vary across subpopulations, and (c) how they vary across countries.

\section{Hypotheses}

\section{Hypotheses on the individual patients' attributes}

H1: Patients with higher chances of survival are preferred over patients with lower chances of survival.

H2: Patients who are admitted first to the hospital are preferred over patients who are admitted later.

H3a: Patients with system-relevant jobs (operationalized as physicians, nurses) are preferred over patients with non-system-relevant jobs (operationalized as professors, cooks) or people without a job.

H3b: Patients with system-relevant jobs (as perceived by the respondent) are preferred over patients with non-system-relevant jobs (as perceived by the respondent).

H4: Female patients are preferred over male patients.

H5: Patients with children are preferred over patients with no children.

H6: Younger patients are preferred over older patients. 


\section{Non-discrimination hypothesis}

H7: Higher chance of survival constitutes the most important or only criterion to select patients.

\section{Social identity/in-group bias hypotheses}

H8a: Older (younger) respondents prefer older (younger) patients over younger (older) patients.

H8b: Male (female) respondents prefer male (female) patients over female (male) patients.

H8c: Respondents with children prefer patients with children more than respondents with no children.

H8d: Respondents with a partisan affiliation prefer patients with the same or ideologically similar partisan affiliation over patients with an ideologically dissimilar partisan affiliation.

\section{Affective polarization hypothesis}

H9: For respondents with strong levels of affective polarization, patients' partisanship constitutes a more important criterion than for respondents with low levels of affective polarization.

H10: For partisans a patients' partisanship constitutes a more important criterion than for independents.

\section{Design Plan}

\section{Study type}

We devise a paired conjoint with forced choice experiment embedded in cross-sectional surveys fielded in the United States, Germany, Brazil, Italy, and Poland.

\section{Blinding}

No blinding is involved in this study. 


\section{Study design}

We conduct a paired between-subject conjoint with forced choice experiment.

Respondens have to choose between two patients that are described by the following seven attributes: gender, age, job, having children, chances of survival, timing of arrival at hospital, and partisanship. The categories of these attributes, which are displayed in the Variables section, are randomly varied to generate different profiles. Each respondent is exposed to four pairs of patients.

\section{Randomization}

Respondents receive the profiles of two patients with categories for each characteristic which are fully randomized with the exception of "arrival at hospital", where the second patient's value is determined by the first patient's value (first $\rightarrow$ second, second $\rightarrow$ first, same time $\rightarrow$ same time). The order of the profile characteristics is randomized across respondents but remains fixed across profile pairs within respondents.

\section{Sampling Plan}

\section{Existing data}

No previously existing data will be analyzed.

\section{Data collection procedures}

Participants will be recruited from online access panels administered by the Respondi company or their partners. No incentives other than the participation incentives provided by Respondi will be given. Participants must be at least 18 years old and reside in the country of interest. Panelists will be sampled according to quotas of gender, age and education.

\section{Sample size}

The German sample will consist of 1,800 respondents. The other country samples will consist of 1,000 respondents each.

We evaluated the power of the conjoint experiment to detect component effects of attributes on the basis of values from previous conjoint studies on this topic and the assumption that attributes had the effect of raising or lowering the average component 
effects by a constant probability amount between 0.025 per level for age job party and arrival time and effects of 0.15 for gender and 0.05 for survival chances. Across a thousand simulations of 1000 subject experiments we computed power greater than 0.8 to detect all but three effects. Specifically the change of job from 'unemployed' to 'cook', from ages 76 to 61 (with power around 0.5 ) and one party effect from indifference (with power around 0.6). All other effects were detected with power 0.9 or higher. Simulating a 1800 subject experiment brought previously higher powered effects to nearly 1 , raised the power of the 'cook' and age 61 component effects to between 0.7 and 0.8 , and the effect of party preference to around 0.9 .

Simulation code for the power analyses can be found at https://github.com/conjugateprior/coronjoint

\section{Variables}

\section{Manipulated variables and outcome measure}

The attributes and attribute levels are provided in Table 1. Figure 1 shows how the experiment is introduced with an explanation.

Table 1: Patient attributes and attribute levels

\begin{tabular}{|c|c|}
\hline Gender & Female, male \\
\hline Age & $27,42,61,76$ \\
\hline Children & Yes, no \\
\hline Job & Unemployed, Physician, Nurse, Professor, Cook \\
\hline Partisanship & $\begin{array}{l}\text { USA: Republican, Democrat, Independent } \\
\text { Germany: AfD, Grüne, No party preference } \\
\text { Brazil: PSL/Aliança (Bolsonaro), PT (Lula), No party } \\
\text { preference } \\
\text { Poland: PiS, PO, No party preference } \\
\text { Italy: Lega, Italia Viva, No party preference }\end{array}$ \\
\hline $\begin{array}{l}\text { Chance of } \\
\text { survival }\end{array}$ & $20 \%, 50 \%, 80 \%$ \\
\hline $\begin{array}{l}\text { Arrival at } \\
\text { hospital }\end{array}$ & $\{$ First, Second $\},\{$ Second, First $\},\{$ Same time, Same time $\}$ \\
\hline
\end{tabular}


Figure 1: Explanation of conjoint task

\section{Please read the following very carefully.}

Very high numbers of COVID-19 (coronavirus) cases would overwhelm the healthcare system. In extreme cases, medical staff would then have to decide which patients should receive intensive medical care and which should not. We would like to know how you would decide this question.

In the following you will see pairs of patients with differing characteristics. Please look carefully at the two patient profiles and tell us which patient you would prioritize for access to intensive medical care.

Note: Although these are not profiles of real patients, we are aware that this kind of decision could be unpleasant or repulsive to you. Therefore, if you do not want to make these decisions, you can skip the questions without answering them.

\section{Please think again of the questions you just answered.}

What characteristics of a patient would be most important to you in deciding who should have access to intensive care first? Note: You can name characteristics mentioned in the questions just answered as well as other characteristics.

\section{Additionally measured variables}

\begin{tabular}{|l|l|l|}
\hline Variable & Question & Scale \\
\hline Gender & Please state your gender & Male, Female, Other \\
\hline Year of birth & $\begin{array}{l}\text { Would you please tell us your } \\
\text { year of birth? }\end{array}$ & $1920-2005$ \\
\hline Age & 2020 - year of birth \\
\hline Children & Do you have children? & $\begin{array}{l}\text { No, Yes 1 child, Yes 2 } \\
\text { children, Yes 3 children, } \\
\text { Yes 4 or more children }\end{array}$ \\
\hline Job employment status & What is your current & Unemployed, [other \\
\hline
\end{tabular}




\begin{tabular}{|c|c|c|}
\hline & employment status? & categories] \\
\hline Job & $\begin{array}{l}\text { What is/was the name or title } \\
\text { of your main job? }\end{array}$ & Open item \\
\hline Partisan affiliation & $\begin{array}{l}\text { What do you think about the } \\
\text { political parties in general ? }\end{array}$ & $\begin{array}{l}\text { "I have a very negative } \\
\text { view of this party" }(-5) \text { to "I } \\
\text { have a very positive view of } \\
\text { this party" }(+5)\end{array}$ \\
\hline Affective polarization & \multicolumn{2}{|c|}{$\begin{array}{l}\text { Absolute difference between partisan affiliation ratings of } \\
\text { parties under study in conjoint experiment }\end{array}$} \\
\hline Partisanship (US) & \multicolumn{2}{|c|}{$\begin{array}{l}\text { Generally speaking, do you usually think of yourself as a } \\
\text { Republican, a Democrat, an independent, or what? } \\
\text { - Republican } \\
\text { - Democrat } \\
\text { - Independent } \\
\text { [lf Democrat/Republican] Would you call yourself a strong } \\
\text { Democrat/Republican or a not very strong } \\
\text { Democrat/Republican? } \\
\text { - Strong Democrat/Republican } \\
\text { - Not very strong Democrat/Republican } \\
\text { [If Independent] Do you think of yourself as closer to the } \\
\text { Republican Party or to the Democratic Party? }\end{array}$} \\
\hline $\begin{array}{l}\text { Partisanship (Other } \\
\text { Countries) }\end{array}$ & \multicolumn{2}{|c|}{$\begin{array}{l}\text { In [country], many people tend to support a certain political } \\
\text { party for a long time, although they also vote for another } \\
\text { party from time to time. How is that with you: Are you } \\
\text { generally inclined towards a particular party? And } \\
\text { if so, which one? } \\
\text { [If Party] Wie stark oder wie schwach neigen Sie - alles } \\
\text { zusammengenommen - der Partei [..] zu? } \\
\text { - strong } \\
\text { - somewhat strong } \\
\text { - moderate }\end{array}$} \\
\hline
\end{tabular}

1 In Germany, the question will be asked as part of a later wave in the survey to the same respondents. 


\begin{tabular}{|l|l|l|}
\hline & \multicolumn{1}{|c|}{$\begin{array}{l}\text { - somewhat weak } \\
\text { weak }\end{array}$} \\
\hline Job relevance & $\begin{array}{l}\text { How essential do you } \\
\text { consider the following } \\
\text { professional groups to keep a a } \\
\text { country running? }\end{array}$ & $\begin{array}{l}\text { Categories: Doctors, } \\
\text { Nurses,Cooks, Journalists, } \\
\text { Professors, Police officers } \\
\text { Scale: Not essential at all, } \\
\text { Not very essential, } \\
\text { Somewhat essential, Very } \\
\text { essential, Don't know }\end{array}$ \\
\hline $\begin{array}{l}\text { Perceived job system } \\
\text { relevance }\end{array}$ & $\begin{array}{l}\text { Jobs rated as "Very essential" or "Somewhat essential" } \\
\text { coded as system-relevant, jobs rated as "Not essential at } \\
\text { all" or "Not very essential" coded as non-system-relevant }\end{array}$ \\
\hline
\end{tabular}

\section{Analysis Plan}

\section{Statistical models}

We will estimate Average Marginal Component Effects (AMCEs) and Average Component Interaction Effects (ACIE) for the profile attribute. Those effect estimates are equivalent to OLS estimates. For the estimation we will make use of the $\mathrm{lm}($ ), cluster.vcov () and coeftest () functions provided in the R. In later specifications we will also add respondent characteristics to the model equations.

We first estimate all models separately for different country samples.

The first specification includes only the main effects of the profile attributes (thus operationalizing $\mathrm{H} 1-\mathrm{H} 6$ ). Standard errors will be clustered on respondents. The exact code for this first step of the analysis is as follows.

\section{Hypotheses on the individual patients' attributes}

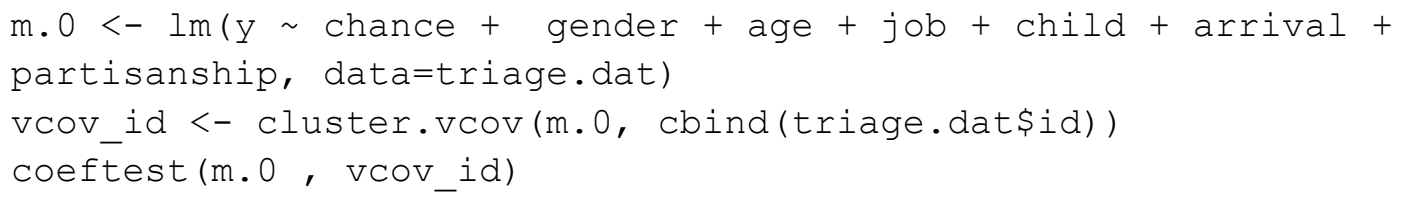

For presentational purposes we will rely on the graphical display of our model results. 


\section{Social identity/in-group bias hypotheses}

The next set of specifications we test the social identity/in-group bias hypotheses. For this we include respondent characteristics (age, gender, pid). Importantly, we will interact this respondent characteristics with profile characteristics (thus operationalizing H8aH8d). Each interaction corresponds to one hypothesis and we will test them separately.

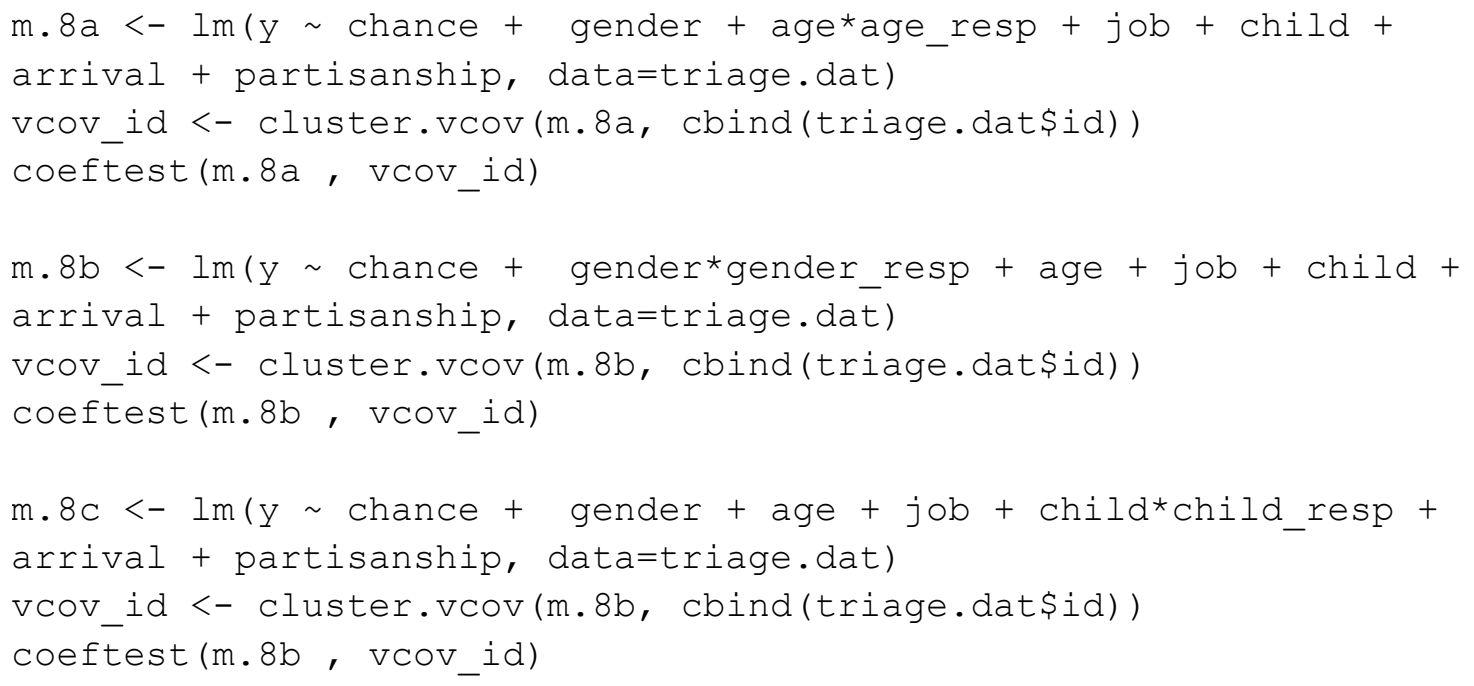

For the partisanship hypothesis we rely on two operationalizations. We first create two dummy variables that take on a value of one if the respondent strongly or somewhat strongly (in the US strong and not very strong) identifies with the respective parties mentioned in the conjoint experiment, and zero otherwise (resp_pid1 and resp_pid2). Secondly, we rely on two measures of party views corresponding to the two parties in the patient profile description (resp_pview1 and resp_pview2). The two operationalizations are used in separate model specifications and interacted with the partisan patient attributes.

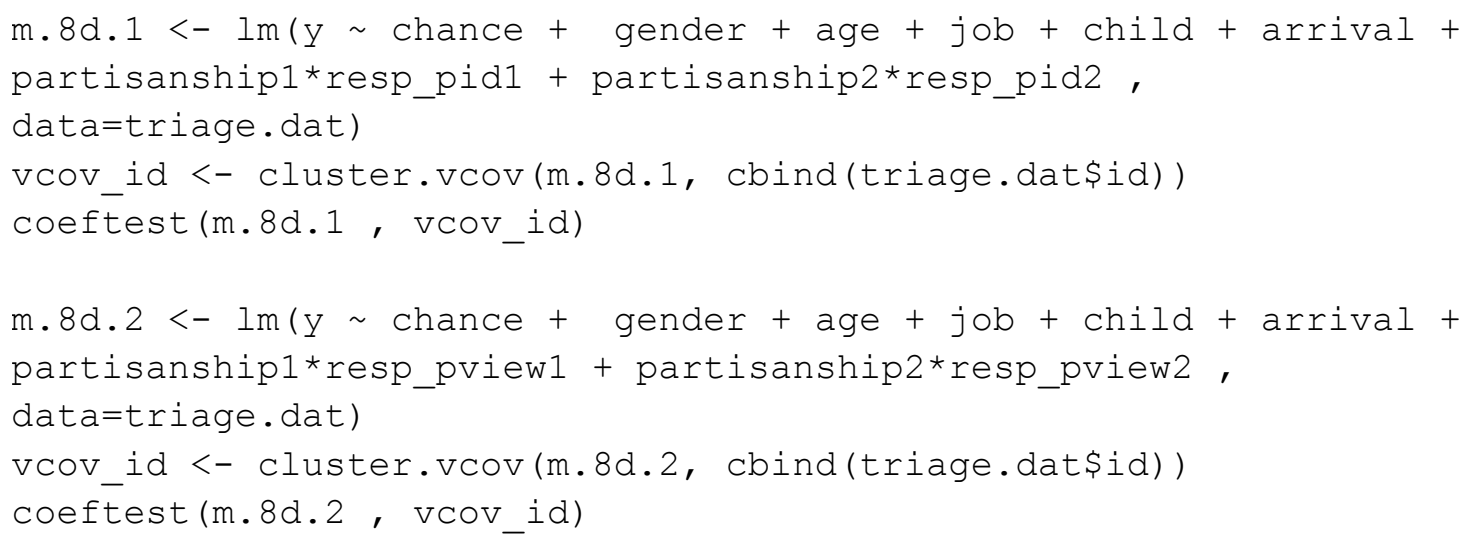




\section{Affective polarization hypothesis}

We also test the affective polarization hypothesis (H9). We construct a measure of affective polarization from the rating scores. For this, we take the absolute difference in the rating scores of the two parties in the conjoint experiment (affective_pol) and include it as covariate in the model specification. The specification includes an interaction with the partisanship attributes.

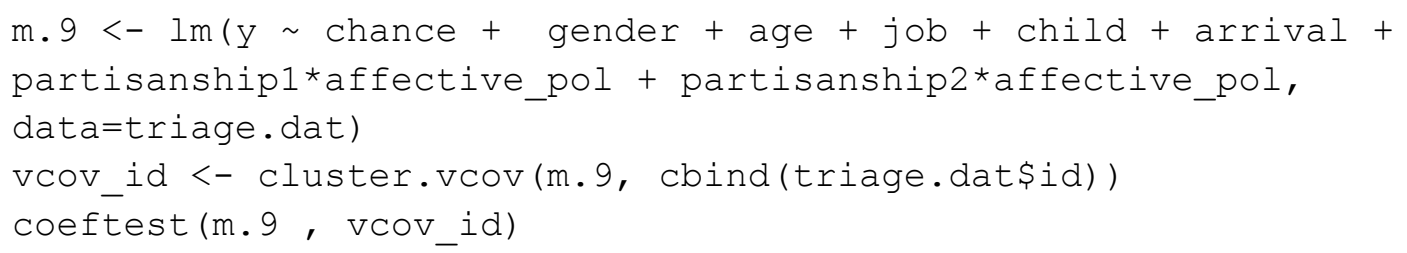

\section{Open Question Format Importance of Attributes}

To test $\mathrm{H} 10$, we further analyze data from the open question format which characteristics of a patient are most important to youtube respondents. We classify the open questions by hand into the different characteristics in the conjoint experiment and a category others. We allow for the naming of multiple categories in one answer. The outcome is the share of respondents that name a certain category.

This allows us to see what characteristics are generally perceived as important and further test $\mathrm{H} 10$. We use a two-sided t-test to analyse if the share of partisans (which we code as all respondents that hold any strong or somewhat strong partisan affiliation, same as above) who give partisanship as a reason is higher compared to respondents without a partisan affiliation.

t.test (importance.party $\sim$ pid.yesno)

\section{Pooled analysis}

We further pool the data to get at the average effects across country contexts. As the sample size varies for the different countries, we weigh by sample size in the pooled analysis. For this we recode the partisan attribute such that partisan_left corresponds to the left party in each country context (Democrats, Grüne, PT (Lula), PO, Italia Viva) and the right parties partisan_right (Republican, AfD,PSL/Aliança (Bolsonaro), PiS, Lega). We cluster standard errors on country and Respondent ID.

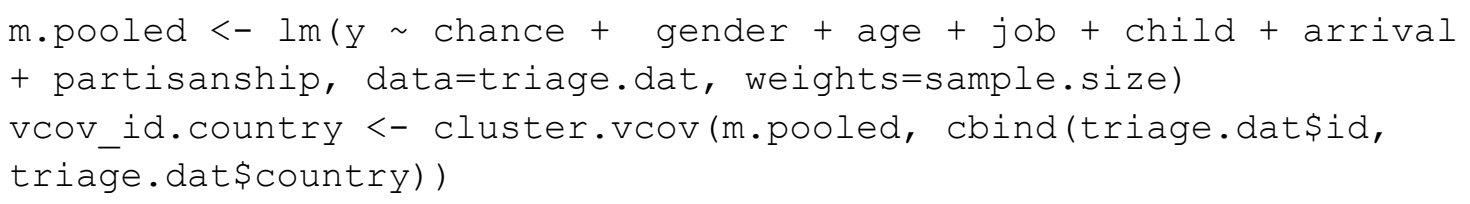


coeftest (m.pooled, vcov_id)

\section{Transformations}

See above under 13.

16. Inference criteria

We will rely on classical frequentist statistical inference and the conventional $p<.05$ cut off for statistical significance. All tests will be two-tailed and while our conjoint experiment includes multiple profile dimensions and attributes, we will not correct the $p$ values for multiple hypotheses.

17. Data exclusion

We will use the full samples and will not exclude any observations from the analysis.

18. Missing data

We will rely on model specific listwise deletion of observations with missing variable values.

19. Exploratory analysis 


\subsection{Deviations from Pre-Analysis Plan}

Although the results we present are based on the pre-analysis plan we registered prior to obtaining the data (see details anonymised regestriation plan 6), there are a few areas in which we had to deviate from the plan. For the sake of transparency, we report each of these changes here:

- We present more descriptive statistics from the survey as pre-registered and that have not been described in the exploratory analysis section of the pre-analysis plan.

- Next to average marginal component effects, we also calculate the marginal means and present them in the appendix.

- In the pre-analysis plan we wrongly stated that we intend to use the "absolute difference in rating scores". To capture if respondents are left-leaning or rightleaning affective polarized we have to use the total difference and report on these results instead.

- For the ease of interpretation the main text, moreover, presents results from a categorical version of the affective polarization measure. This has not been preregistered but makes it easier to interpret the results in terms of in-group and outgroup effects. The appendix still presents the results with the linear interaction (SM 5.6), and probes the robustness using an alternative cut-offs fr the categorical variable $(\mathrm{SM} 5.3$ ).

- We slightly deviate from the pre-analysis plan to evaluate the partisanship hypothesis. We include the interaction of each patient partisanship attribute with both respondent partisanship categories. E.g. partisanship $1^{*}$ resp_pid1 + partisanship2* ${ }^{*}$ resp_pid2 + partisanship2*resp_pid1 + partisanship $1{ }^{*}$ resp_pid2 instead of just partisanship1*resp_pid1 + partisanship2*resp_pid2 in m.8d.1. This permits us to capture in group-favouritism as well as out-group animus.

- We refrain from using the rating scores plus partisanship (model m.8d.2) to test the partisanship hypothesis, as the rating scores are now already part of the revised affective polarization hypothesis. 


\section{References}

Doctors ethical code. https://sip.lex.pl/akty-prawne/akty-korporacyjne/ kodeks-etyki-lekarskiej-286454095. Accessed: 2021-03-25.

Coronavirus: Brazil records third-highest covid-19 infection level. BBC News, May 2020. URL https://www.bbc.com/news/world-latin-america-52719391.

Kretschmann dringt auf scharfen corona-lockdown. Die WELT, Dec 2020. URL https://www.welt.de/regionales/baden-wuerttemberg/article222030166/ Kretschmann-dringt-auf-scharfen-Corona-Lockdown.html.

Lula sobre coronavírus: 'primeiro salvamos o povo, depois a economia'. Notícias, Mar 2020. URL https://noticias.uol.com.br/saude/ultimas-noticias/redacao/ 2020/03/19/primeiro-salvamos-o-povo-depois-a-economia-diz-lula-sobrecoronavirus.htm.

Poland to enter national quarantine starting dec. 28 to fight covid-19. Reuters, Dec 2020. URL https://www.reuters.com/article/health-coronavirus-polandidUSKBN28R233.

Lula: Bolsonaro leading brazil 'to slaughterhouse' over covid-19. The Guardian, Apr 2020. URL http://www.theguardian.com/world/2020/apr/17/lula-bolsonarobrazil-to-slaughterhouse-covid-19-coronavirus.

Italy closes all shops, restaurants as coronavirus cases rise. Time, Mar 2020. URL https://time.com/5801497/italy-shops-restaurants-coronavirus/.

Landtag: Afd-fraktion lehnt lockdown ab: Kritik an schulpolitik. ZEIT online, Dec 2020a. URL https://www.zeit.de/news/2020-12/14/afd-fraktion-lehntlockdown-ab-kritik-an-schulpolitik.

Grüne fordern harten corona-lockdown in sachsen-anhalt. ZEIT online, Dec 2020b. URL https://www.zeit.de/news/2020-12/11/gruene-fordern-hartencorona-lockdown-in-sachsen-anhalt.

Corona: Grünen-palmer fordert lockdown-ende: Es reicht jetzt. wir müssen leben! bild.de, Jan 2021. URL https://www.bild.de/politik/inland/politikinland/corona-gruenen-palmer-fordert-lockdown-ende-es-reicht-jetztwir-muessen-leben-74831930.bild.html. 
Grüne halten schrittweise schulöffnung für richtig. DIE WELT, Jan 2021. URL https://www.welt.de/regionales/berlin/article223907942/Gruene-haltenschrittweise-Schuloeffnung-fuer-richtig.html.

Bolsonaro sabota combate à covid-19, diz relatório: Dw: 13.01.2021. DW.COM, Jan 2021. URL https://www.dw.com/pt-br/bolsonaro-sabota-combate-\%C3\%AOcovid-19-diz-relat\%C3\%B3rio/a-56213559.

Bürgerschaft: Bürgerschaft bis auf afd hält lockdown für nötig. ZEIT ONLINE, Jan 2021. URL https://www.zeit.de/news/2021-01/13/buergerschaft-haeltlockdown-fuer-noetig-nur-afd-nicht.

Agnieszka Barteczko and Pawel Florkiewicz. Poland to begin easing coronavirus curbs from sunday with eye on may vote. Reuters, Apr 2020. URL https://www.reuters.com/article/us-health-coronavirus-polandrestriction-idUSKCN21WOKQ.

Ronald Brownstein. Red and blue america aren't experiencing the same pandemic. The Atlantic, Mar 2020. URL https://www.theatlantic.com/politics/archive/2020/ 03/how-republicans-and-democrats-think-about-coronavirus/608395/.

Flora Charner. Bolsonaro defends joining anti-lockdown protest in brazil. CNN, Apr 2020. URL https://www.cnn.com/2020/04/20/americas/bolsonaro-defendscoronavirus-protest-intl/index.html.

Page Winfield Cunningham. The health 202: Biden isn't taking a hardline lockdown stance, as trump had claimed. Washington Post, Nov 2020. URL https://www.washingtonpost.com/politics/2020/11/19/health-202biden-isnt-taking-hardline-lockdown-stance-trump-had-claimed/.

Holly Ellyatt. Italy passes 10,000 coronavirus cases as national quarantine moves closer to total shutdown. CNBC, Mar 2020. URL https://www.cnbc.com/2020/03/11/ italy-passes-10000-coronavirus-cases.html.

Maria Fiedler. Wie die afd versucht, aus dem corona-tief zu kommen. Der Tagesspiegel. URL https://www.tagesspiegel.de/politik/mit-vollerkraft-gegen-den-lockdown-wie-die-afd-versucht-aus-dem-corona-tiefzu-kommen/25808282.html.

AfD Fraktion. Positionspapier corona-krise - afd-fraktion im deutschen bundestag. AfD, Dec 2020. URL https://www.afdbundestag.de/positionspapier-corona-krise. 
Marie Gediehn. Janosch dahmen (grüne): In der corona-bekämpfung "lockdown über den januar hinaus". swr.online, Jan 2021. URL https: //www.swr.de/swr2/leben-und-gesellschaft/janosch-dahmen-gruene-inder-corona-bekaempfung-lockdown-ueber-den-januar-hinaus-100.html.

Michael Gold. Indoor dining will shut down in new york city again. The New York Times, Dec 2020. URL https://www.nytimes.com/2020/12/11/nyregion/indoordining-nyc.html.

Georg Ismar. Grüne für lockdown-verschärfung wegen mutiertem corona-virus. Der Tagesspiegel, Jan 2021. URL https://www.tagesspiegel.de/politik/ millionen-beschaeftigte-von-infektionen-bedroht-gruene-fuer-lockdownverschaerfung-wegen-mutiertem-corona-virus/26783792.html.

Susanne Jöbges, Rasita Vinay, Valerie A Luyckx, and Nikola Biller-Andorno. Recommendations on covid-19 triage: international comparison and ethical analysis. Bioethics, 2020.

Werner Krause, Pola Lehmann, Matthieß Theres, Nicolas Merz, Sven Regel, and Bernhard Weßels. The manifesto data collection: South america. version 2020b, 2020. URL https://doi.org/10.25522/manifesto.mpdssa.2020b.

Ryan Fahey For Mailonline. Poland closes all schools, museums and cinemas amid coronavirus. Daily Mail Online, Mar 2020. URL https: //www.dailymail.co.uk/news/article-8099501/Poland-closes-schoolsmuseums-cinemas-amid-coronavirus.html.

Georg Marckmann, Gerald Neitzke, Jan Schildmann, Andrej Michalsen, Jochen Dutzmann, Christiane Hartog, Susanne Jöbges, Kathrin Knochel, Guido Michels, Martin Pin, et al. Decisions on the allocation of intensive care resources in the context of the covid-19 pandemic. Medizinische Klinik-Intensivmedizin und Notfallmedizin, pages $1-8,2020$.

ByMarek Matraszek. Being \& nothingness: The polish election that wasn't. Poland Today, May 2020. URL https://poland-today.pl/the-polish-election-thatwasnt-expert-insight/.

Ryan C Maves, James Downar, Jeffrey R Dichter, John L Hick, Asha Devereaux, James A Geiling, Niranjan Kissoon, Nathaniel Hupert, Alexander S Niven, Mary A 
King, et al. Triage of scarce critical care resources in covid-19: an implementation guide for regional allocation an expert panel report of the task force for mass critical care and the american college of chest physicians. Chest, 2020. URL https://doi.org/10.1016/j.chest.2020.03.063.

Gabriela Mello and Rodrigo Viga Gaier. Brazil lockdowns, attacked by bolsonaro, begin to slip. Reuters, Apr 2020. URL https://www.reuters.com/article/us-healthcoronavirus-brazil-lockdown-idUSKCN21R30B.

Luca Monticelli. Coronavirus, la lega contro il "superdecretone" del governo: non ci stanno consultando. lastampa.it, Mar 2020. URL https: //www.lastampa.it/politica/2020/03/14/news/coronavirus-la-lega-controil-superdecretone-del-governo-una-vera-e-propria-manovra-1.38592850.

Camila Vantini Capasso Palamim and Fernando Augusto Lima Marson. Covid-19-the availability of icu beds in brazil during the onset of pandemic. Annals of global health, 86(1), 2020.

Gianni Santamaria. Coronavirus. proposta renzi, un coro di no alla "riapertura" dell'italia. Avvenire, Mar 2020. URL https://www.avvenire.it/attualita/pagine/ contro-la-riapertura-ipotesi-renzi-coronavirus.

Franco Stefanoni. Coronavirus, speranza a salvini: "nessun piano segreto del governo. sei un leader piccolo". Corriere della Sera, Sep 2020. URL https://www.corriere.it/politica/20_settembre_06/coronavirus-speranzasalvini-nessun-piano-segreto-governo-sei-leader-piccolo-d47e879ef031-11ea-9471-e3973f870fbb.shtml.

Veronica Stracqualursi. Biden says he would shut down us to stop coronavirus if scientists recommended it. CNN, Aug 2020. URL https://www.cnn.com/2020/08/22/ politics/biden-coronavirus-shutdown/index.html.

Giselda Vagnoni. Impossible dilemma? world watches italy as businesses plead to return to work. Reuters, Apr 2020. URL https://www.reuters.com/article/us-healthcoronavirus-italy-industry-ins-idUSKBN21P27C.

Marco Vergano, Guido Bertolini, Alberto Giannini, Giuseppe R Gristina, Sergio Livigni, Giovanni Mistraletti, Luigi Riccioni, and Flavia Petrini. Clinical ethics recommendations for the allocation of intensive care treatments in exceptional, resource-limited 
circumstances: the italian perspective during the covid-19 epidemic. 2020. URL https://bit.1y/2UyQ6I3.

K. P. Vogel, J. Rutenberg, and L. Lerer. The quiet hand of conservative groups in the anti-lockdown protests. The New York Times, Apr 2020. URL URL:https:// www.nytimes.com/2020/04/21/us/politics/coronavirus-protests-trump.html

Andrea Volkens, Tobias Burst, Werner Krause, Pola Lehmann, Theres Matthieß, Nicolas Merz, Sven Regel, Bernhard Weßels, and Lisa Zehnter. The manifesto data collection. manifesto project (mrg/cmp/marpor). version 2020b, 2020. URL https://doi.org/ 10.25522/manifesto.mpds.2020b.

Myah Ward. Coronavirus lockdowns pit republican governors against democratic mayors. POLITICO, Apr 2020. URL https://www.politico.com/news/2020/04/21/ coronavirus-pits-republican-governors-democratic-mayors-198858.

Katy Watson. Coronavirus: Brazil's bolsonaro in denial and out on a limb. BBC News, Mar 2020. URL https://www.bbc.com/news/world-latin-america-52080830.

Justin Wingerter and Saja Hindi. "my body, my choice": Inside colorado's growing anti-shutdown movement. The Denver Post, Apr 2020. URL https://www.denverpost.com/2020/04/25/coronavirus-shutdown-protestscolorado-politics/.

Alex Woodward. Why five states are refusing 'lockdowns' against coronavirus. The Independent, Apr 2020. URL/https://www.independent.co.uk/news/world/americas/ coronavirus-us-states-lockdown-spring-break-a9442746.html.

Tomasz Zalewski. Poland divided over elections and covid restrictions. Atlantic Council, May 2020. URL https://www.atlanticcouncil.org/blogs/new-atlanticist/ poland-divided-over-elections-and-covid-restrictions/.

Jeff Zeleny. Why these 8 republican governors are holding out on statewide stay-athome orders. CNN, Apr 2020. URL https://www.cnn.com/2020/04/04/politics/ republican-governors-stay-at-home-orders-coronavirus/index.html. 